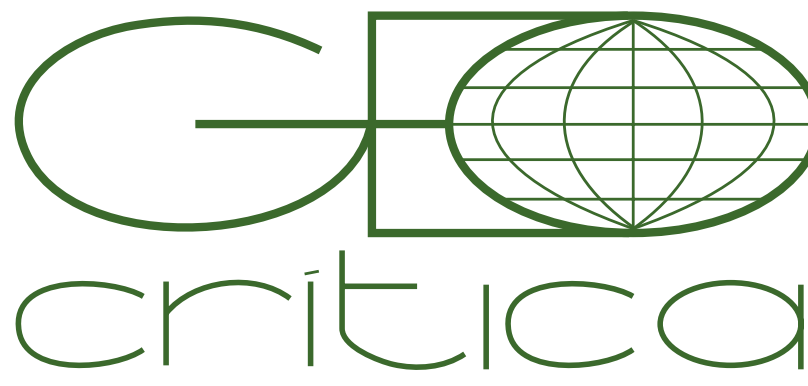

\section{Scripta Nova}

Revista Electrónica de Geografía y Ciencias Sociales Universitat de Barcelona

ISSN: $1138-97$

Vol. XXIII. Núm. 622

15 de septiembre de 2019

\title{
EN TORNO A LA RIADA DE 1957 EN LA CIUDAD DE VALENCIA
}

\author{
María Jesús Romero Aloy \\ maroal1@urb.upv.es \\ Mercedes Almenar-Muñoz \\ meralmuo@urb.upv.es
}

\section{Vicente Fullana Serra \\ vfullana@hma.upv.es \\ Universitat Politécnica de València}

Recibido 6 de octubre de 2018; Devuelto para correcciones 12 de enero de 2019; Aceptado: 30 de mayo de 2019

\section{En torno a la riada de 1957 en la ciudad de Valencia (Resumen)}

Las inundaciones en España constituyen la catástrofe natural que durante siglos ha producido los mayores daños tanto materiales como en pérdida de vidas humanas, por lo que la lucha contra los efectos negativos de este riesgo ha sido históricamente una constante de la planificación hidrológica y de protección civil.Con motivo del 60 aniversario de la catastrófica inundación que asoló la ciudad de Valencia, se reflexiona sobre la suficiencia de las infraestructuras que se construyeron para defender la ciudad de posibles inundaciones, concluyéndose que el riesgo no ha sido erradicado y que debieran adoptarse medidas concretas en aras de una mayor seguridad. Se analiza el tratamiento que los planes de origen estatal, autonómico y local realizan sobre Valencia y área circundante, con los correspondientes pronunciamientos sobre los niveles de riesgo de inundación, con las medidas y limitaciones a observar por el planeamiento territorial sobre las clasificaciones de suelo, usos y régimen urbanístico.

Palabras clave: inundaciones, riesgos naturales, obras de defensa, Valencia.

\section{Around the flood of 1957 in the city of Valencia (Abstract)}

The floods in Spain constitute the natural catastrophe that for centuries has produced the greatest material damage and loss of human lives. As a result, the fight against the negative effects of this risk has historically been a key element of hydrological planning and civil protection. In the 60th anniversary of the catastrophic flood that struck the city of Valencia, a discussion is made on the sufficiency of the infrastructures that were built to defend the city against new possible floods, reaching the conclusion that the risk has not been completely eradicated, and that new measures should be adopted in order to guarantee a higher degree of security. An analysis is made on the treatment that the plans on state, regional and local scale have over the city and the surrounding area, with the corresponding pronouncements made on the levels of flooding risk, and with the measures and limitations that must be observed in territorial and urban planning regarding the classifications of the soil, its uses and the urban regime.

Key words: severe floods, natural risks, defense works, Valencia. 
En octubre de 2017 se han cumplido sesenta años de la gran inundación que asoló la ciudad de Valencia (España) por el desbordamiento del río Turia, causando la muerte a un centenar de personas y enormes daños materiales en el conjunto urbano y en las infraestructuras. La finalidad de este trabajo va más allá de hacer presente una justificada efeméride. A lo largo de la historia, la ciudad de Valencia ha sufrido numerosas inundaciones y la gran catástrofe anterior a la de 1957, tuvo lugar en 1897, es decir, justamente otros 60 años antes. En 1957, por tanto, casi ningún habitante de la ciudad guardaba memoria de aquél lejano suceso. Una lamentable característica de la condición humana, apremiada por las urgentes solicitaciones del momento presente, es la pérdida de consciencia del pasado, sobre todo si con el transcurso de los decenios ningún acontecimiento impulsa a volver la mirada hacia atrás. Como se verá más adelante, la inundación de 1957, por su gravedad, dio lugar a la intervención del Estado de la Nación promulgando las correspondientes leyes que propiciarían la construcción de importantes obras públicas tendentes a evitar nuevas catástrofes y que, además, han sido la base del desarrollo urbano de la ciudad. Sin embargo, en las últimas décadas, en un nuevo contexto cultural en el que se ha desarrollado una notable sensibilidad hacia los temas urbanos y medioambientales, ha surgido alguna reflexión en orden a revisar la seguridad de la ciudad frente a la amenaza secular. Esta reflexión se produce en el marco vigente de una importante normativa emanada de la Unión Europea, y de otras disposiciones y planes procedentes del Gobierno de la Nación y del Nivel Regional o Autonómico, lo cual demuestra la preocupación por evitar los graves daños que pueden derivarse del riesgo hídrico. Las conclusiones que se trata de obtener no son meramente especulativas, sino que tienen por objeto alertar ante un posible y grave riesgo que, a nuestro juicio, sigue latente en el área según la fundamentación que se contiene en este trabajo.

\section{En el sexagésimo aniversario de la gran inundación}

Durante los días 13 y 14 de octubre de 1957, la ciudad de Valencia (España) sufrió una catastrófica inundación producida por el desbordamiento del río Turia que discurría por la ciudad. En aquel entonces contaba con una población de 505.066 habitantes mientras que la de hoy alcanza 790.201 habitantes y es la capitalidad de un área metropolitana de 1.744.201 habitantes ${ }^{1}$.

La ciudad de Valencia fue fundada por Roma en el año 138 A.C. ${ }^{2}$ sobre una superficie aterrazada del río Turia, en la Hispania Citerior. Se fundó sobre una isla fluvial, emplazamiento relativamente frecuente en ciudades mediterráneas, como es el caso de Montpellier, Arlés, Rávena o la propia Roma. Esta ubicación a lo largo de la

1 Ayuntamiento de Valencia. https//www.valencia.es/ayuntamiento/laciudad.insf/vDocumentos, Olcina, 1999.

2 Boix, 1845, p.14. “Tito Livio dice (epit.55), que el cónsul Junio Bruto, durante su gobierno en España, concedió a los soldados que habían seguido las banderas de Viriato algunos campos y una población que se llamó Valencia". 
historia se demostró enormemente vulnerable ante el riesgo hídrico³. En concreto la inundación de 1957 afectó a una zona urbana de 1120 hectáreas, más 1091 hectáreas. de suelo colindante no urbano, con una amplitud de siete km. El agua llegó a alcanzar un nivel de $5 \mathrm{~m}$. en el interior de la ciudad $\mathrm{d}^{4}$. El número de víctimas mortales ascendió a $99^{5}$ y las pérdidas materiales se evaluaron entre 3.000 y 5.000 millones de pesetas. Tras la catástrofe, el gobierno de la nación, junto con el gobierno local afrontaron la necesaria tarea de evitar en el futuro nuevas catástrofes y se optó por el desvío del río Turia mediante la construcción de un nuevo cauce, desviando el río en la dirección sur a partir de un punto anterior a su penetración en la ciudad (Solución Sur $)^{6}$. Lo cierto es que, con el paso del tiempo, se han producido reflexiones ${ }^{7}$ sobre la suficiencia de esta solución y la vulnerabilidad de la ciudad en el contexto del vigente marco sociopolítico y conceptual muy distinto al del año 1957.

El concepto de vulnerabilidad ofrece unos perfiles muy amplios y, en la mayoría de los casos, hace referencia a la vulnerabilidad social ${ }^{8}$ pero también comprende las condiciones del entorno en el que se inserta la vida cotidiana y conceptualmente pueden distinguirse tres factores integrantes, tales como la exposición al riesgo, la susceptibilidad y la capacidad de reacción. La exposición al riesgo se ve como la precondición física de verse afectado por un impacto de una amenaza natural'. La exposición a amenazas es un "external stress placed on (peoples) livelihoods and well-be$i^{\prime \prime \prime 10}$. Es en el factor de susceptibilidad en el que se inscribe plenamente nuestro trabajo, ya que ésta se entiende como la precondición a sufrir un daño debido a las condiciones residenciales desventajosas ${ }^{11}$ tales como una infraestructura inadecuada, la falta de acceso a los servicios básicos o ciertos materiales de construcción "inestables"12. De los anteriores elementos nos vamos a centrar en este trabajo, de modo principal, en el aspecto de infraestructura inadecuada.

La necesidad de disponer de una infraestructura de defensa suficiente se desprende de los datos históricos que recogen los graves eventos hídricos que han afectado a la ciudad de Valencia. Desde el año 1321 a 1957 se han registrado 24 grandes avenidas (1328, 1340, 1358, 1406, 1427, 1475, 1517, 1540,1581, 1589, 1590, 1610,

3 Fita, 1884, p. 137. Recoge inscripción latina en el pretil del río en la que se deja constancia de las inundaciones. ("marmor turiae: Celebríores TURIAE, ubi inventa ISIDIS inscriptio aquarum inundationes, quae agros occuparunt, confudederuntque, urbique VALENTIAE ruina mminitatae sunt".)

4 Cruz, 1959, p.35.

5 Pérez, 1997, p.169.

6 La llamada Solución Sur está prevista en la Ley 81/1961, de 23 de diciembre, cuyo art. 2 comprende: a) Obras hidráulicas. Construcción del nuevo cauce del río con una longitud de doce mil seiscientos noventa y dos metros, ancho de doscientos metros y capacidad de desagüe de cinco mil metros cúbicos por segundo.

7 Llinares et al, 2014.

8 Welz \& Krellenberg, 2016, p. 251-272.

9 Fuch, S. Kuhlicke, C. \& Meyer, V, 2011.

10 Adger-Kelli, 1999, p. 253.

11 Birkmann, Cardona, Carreño, Barbat, Pelling, Schneiderbauer, ... Welle, 2013, p. 193-211.

12 Kuhlicke, Scolobig, Tapsell, Steinführer, \& de Marchi, 2011. 
$1651,1672,1731,1776,1783,1845,1860,1864,1870,1897$, y finalmente $1957^{13}$ ) que afectaron a la ciudad, algunas de ellas de manera verdaderamente catastrófica, lo que supone que el período de retorno o intervalo de recurrencia es de 27 años. La conclusión certera es que se da un promedio de dos grandes inundaciones cada siglo e incluso con frecuencia más alta ${ }^{14}$, que es la zona de mayor riesgo de toda Europa de sufrir grandes avenidas ${ }^{15}$. De las 17 comunidades autónomas en las que se estructura el Estado Español, la Comunidad Valenciana es la que figura a la cabeza por pérdidas originadas por las inundaciones en el período 1987-2001 en el que ascienden a 3.353.227.646 Euros ${ }^{16}$. Históricamente la defensa de la ciudad de Valencia frente a las inundaciones se articuló de modos diversos. Entre ellos, las murallas tuvieron la doble función de defensa militar y también como muro de contención de las avalanchas. La muralla septentrional de la ciudad construida en tiempos de Pedro el Ceremonioso en 1356 perduró inalterable hasta 1865.

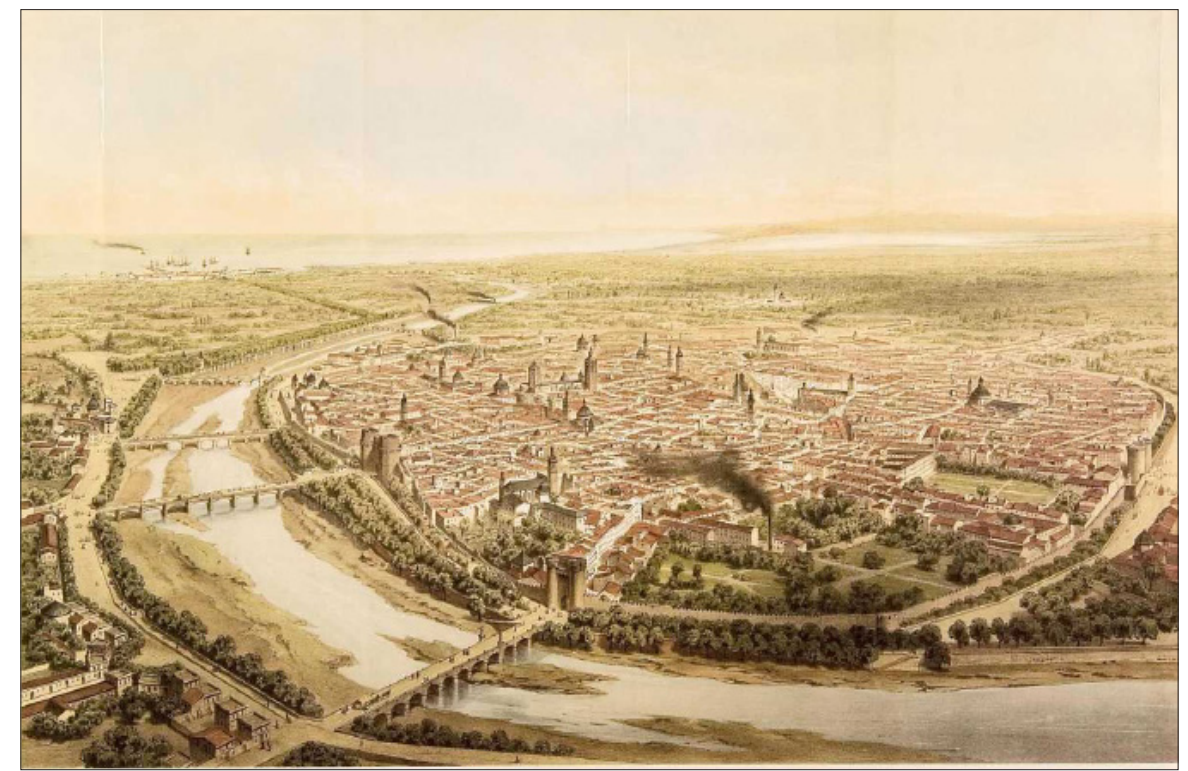

Figura 1: Vista de la ciudad de Valencia por Alfred Guesdon (1863)

Fuente: Biblioteca Digital Hispánica (Biblioteca Nacional de España).

<http://bdh-rd.bne.es/viewer.vm?id=0000021106 > [Consulta: 5 de marzo de 2019].

Se crearon instituciones administrativas cuya misión era el adecuado mantenimiento de las defensas, como fue la Junta de Murs i Valls ${ }^{17}$ y la Fabrica Nova del Riu ${ }^{18}$

13 Melió, 1991, p. 71. Entre el 30 de agosto de 1500 y el 14 de octubre de 1957 recoge 78 riadas, clasificándolas de riada ordinaria, extraordinaria y catastrófica.

14 Pérez, 1997, p. 232.

15 Saurí, Serra Olcina, \& Vera, 2011, p. 30-39: Gil-Olcina, 1989: Gil-Olcina, 1991.

16 González, 2009, p. 14.

17 Llop, 1675. La Junta de Murs i Valls fue instituida por Pedro el Ceremonioso en virtud del Real Privilegio del 24 de agosto de 1358 a la que correspondía la obligación de construir y mantener las murallas y fosos defensivos, la red de alcantarillado, y las obras hidráulicas.

18 Melió, 1991, p. 71. Por el Consell General, con fecha de 18 de septiembre de 1590, se acordó cumplimentar el Real mandato de 29 de agosto de 1590 de Felipe II, estableciéndose la base financiera para la Fábrica Nova del Riu, cuya misión era construir exclusivamente obras con la suficiente solidez y fortaleza para poder resistir el embate de las avenidas del río Turia. La institución estaba bajo el patrocinio de la Corona, el Consell General y la Junta de Muros y Valles. 
creada a raíz de la catastrófica inundación de 1589 y cuya misión era la construcción de pretiles a ambas orillas del río. La literatura poética no deja de hacerse eco del terrible azote $^{19}$.

Las condiciones ambientales del área en la que se asienta la ciudad de Valencia explican claramente la amenaza que desde antiguo se ha cernido sobre la ciudad. En efecto, el río Turia mide unos $300 \mathrm{kms}$. de longitud y en su parte alta y media está regulado por grandes embalses ${ }^{20}$. La parte baja, más próxima a Valencia, está amenazada por importantes riesgos, al acumular las precipitaciones recogidas en el territorio que abarca desde la costa hasta cadena montañosa que circunda la llanura. Los estudios climatológicos indican que el cauce bajo del río Turia es uno de los más expuestos a grandes lluvias torrenciales, en concreto al fenómeno denominado DANA/ "gota fría" ${ }^{21}$, calificado como el tercer lugar de mayor riesgo a nivel mundial $^{22}$. En concreto, la inundación de 1957 tuvo su origen en que, en ambos procesos, la convección forzada, y la mezcla al nivel bárico de $500 \mathrm{mb}$ originaba fuerte condensación, con la consiguiente liberación de calor que intensificaba el movimiento ascendente del aire, el cual, al sobrepasar la isoterma de $-20^{\circ}$, dio lugar a una creciente producción de cristales de hielo, necesarios para la iniciación de lluvias copiosas ${ }^{23}$. Un contexto más amplio de esta situación atmosférica ya fue estudiado por otro autor en el mismo sentido ${ }^{24}$. En el Apéndice B del Documento Básico de Salubridad, Evacuación de Aguas (CTE BB-HS), del Código Técnico de la Edificación, la ciudad de Valencia se encuentra situada en la denominada Zona Climática B, entre las isoyetas 60 y 70. Según la tabla Bl del DB HS-5 se obtiene una intensidad pluviométrica de $135 / \mathrm{mm} /$ hora, claramente elevada.

\section{El nuevo cauce y la solución Sur}

Como se ha dicho, la salvaguarda de la ciudad se confió a la construcción de una gran obra hidráulica, consistente en la realización de un nuevo cauce artificial en dirección Sur, capaz de canalizar las futuras avenidas. Este proyecto contaba con el antecedente de un desvío en la misma dirección, según proyecto presentado en 1891 ante el Ministerio de Fomento por Joaquín Llorens y Fernández de Córdova que no

19 Ibn Khafaja, (Poeta andalusí 1059-1138). El mar de la riada / oleadas de barro; / el cielo generoso en lágrimas; / los edificios resquebrajados, / humillados como cautivos / ante el tirano / los edificios se venían abajo / inclinándose a tierra / como harían las comisiones / delante se los reyes / se diría que imitaban / a los fieles en oración.

20 Embalses del río Turia en sus cuencas alta y media: Arquillo de San Blas (21,0 Hm3), Benagéber 221,3 Hm3), Loriguilla (73,2 Hm3) y Buseo (7,5 Hm3). Fuente: Ministerio de Agricultura y Pesca, Alimentación y Medioambiente, Confederación Hidrográfica del Júcar.

21 Martí, 2003. DANA (Depresión Aislada de Niveles Altos) es "una depresión cerrada en altura que se ha aislado y separado completamente de la circulación asociada al chorro, y que se mueve independientemente de tal flujo llegando, a veces, a ser estacionaria o, incluso, retrógrada (su desplazamiento es, en estos casos, de dirección este-oeste").

22 Camarasa, 1993.

23 García, \& Carrasco, 1958.

24 Zimmerschied, 1949, p.55. 
se llevó a efecto ${ }^{25}$. En el proyecto que ahora tratamos, la iniciativa fue aprobada en el Consejo de Ministros de 22 de julio de 1958 y las Cortes Españolas, mediante la Ley $81 / 61^{26}$ establecieron las directrices de financiación.

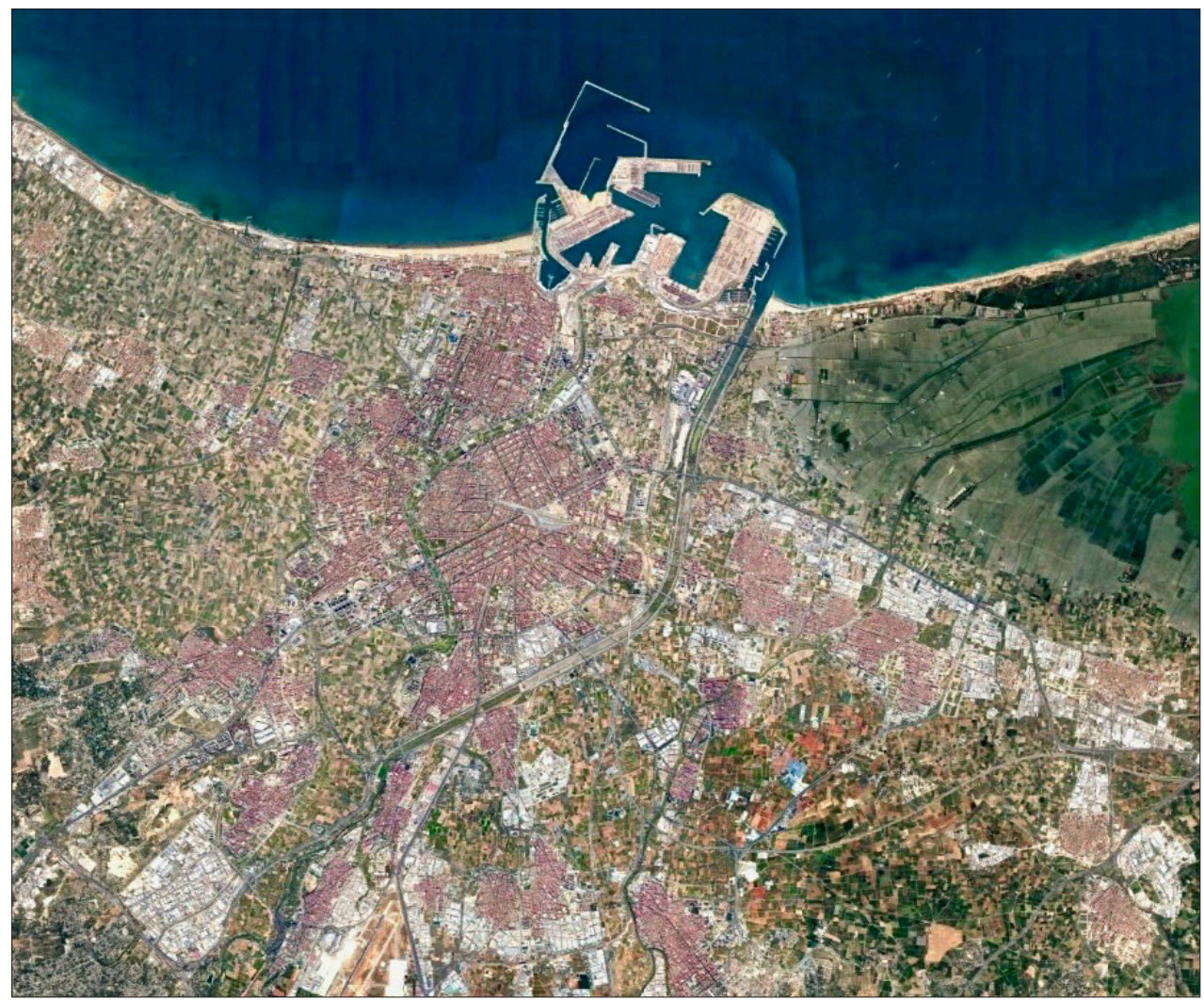

Figura 2: Fotografía aérea en la que se pueden apreciar los dos cauces. A la izquierda, realizando una apreciable curva, el cauce antiguo en la zona céntrica de la ciudad, hoy parque urbano. A la derecha de la imagen el nuevo cauce con un trazado inicialmente rectilíneo. Posteriormente despliega una amplia curva y desemboca en el mar.

Fuente: Confederación Hidrográfica del Júcar.

La gran envergadura del proyecto llevo consigo la modificación del Plan General de Ordenación Urbana de Valencia, adaptándolo a la Solución Sur ${ }^{27}$. Este plan urbanístico ha sido el eje de la transformación de la ciudad y estuvo en vigor hasta 1988, fecha en la que se revisó. Por otra parte, una vez construido el nuevo cauce, los terrenos del antiguo, posicionados por el desarrollo urbano como un área céntrica,

25 Almela y Vives, 1959, p. 27.

26 La Ley 81/1961 de 23 de diciembre sobre el Plan Sur de Valencia, en el artículo segundo prevé, entre otras, la siguiente obra hidráulica: Construcción del nuevo cauce del río con una longitud de doce mil seiscientos noventa y dos metros, anchura de doscientos metros y capacidad de desagüe de cinco mil metros cúbicos por segundo.

27 Selva, 2014, p. 59. "La construcción del nuevo cauce adquirió unas dimensiones hasta entonces no igualadas en la obra civil (se excavaron 11.173.000 m3 de tierra y se ejecutaron más de $420.000 \mathrm{~m} 3$ de hormigón armado, además de $71 \mathrm{~km}$ de acequias) con la diferencia fundamental con respecto a la red arterial de que ésta sí recibió una financiación adecuada... En resumen, el Plan General de Valencia y su Comarca de 1966 supuso el mejor manifiesto de la memoria planificadora de su tiempo: un ambicioso documento que extrapoló los anteriores postulados fundamentándose en una confianza ciega en el desarrollo económico y la capacidad de las infraestructuras para resolver los problemas urbanos". 
fueron destinados en una superficie de 110 hectáreas ${ }^{28}$, a un gran parque urbano que constituye uno de los grandes atractivos de la ciudad ${ }^{29}$.

La capacidad de desagüe del nuevo cauce se calculó en base a la punta de la riada de 1957, que oficialmente se estimó en 3.700 m3/segundo. La estimación de caudal efectuada en el año 1957 por la Confederación Hidrográfica del Júcar en el kilómetro 297.7 del río Turia, fue una medición realizada mediante la fórmula de Manning, actualmente muy superada. En efecto, las estimaciones hechas tomando datos de un tramo de río no son fiables porque en las fórmulas (Manning y otras similares) figura un factor que depende de la rugosidad de la superficie mojada (fondo y cajeros del cauce) que es prácticamente imposible de ajustar. El caudal podría estimarse con indudables garantías en un aliviadero de una presa (por ejemplo, en la toma de agua potables en el término de Manises por donde discurre el río) o en una estación de aforos como la situada cerca de dicha presa. Pero esos datos han de tomarse en el momento de la avenida. Como ya se ha dicho, la medición del caudal se hizo sin tener en cuenta estas circunstancias. Este es el motivo por el que la medición ofrece razonables e importantes reparos en orden a su exactitud.

Frente a la anterior estimación se sitúa la que se contiene en el estudio "Lluvias de intensidad y extensión extraordinaria causantes de las inundaciones de los días 13 y 14 de octubre de 1957 en las provincias de Valencia, Castellón y Alicante"30 en el que se afirma que "el volumen de la avenida hubo de ser en algunos momentos superior a los 6.000 metros cúbicos por segundo". En relación con el referido estudio deben tenerse en cuenta diversos factores que avalan su validez. En primer lugar, el alto nivel profesional de los redactores, en segundo lugar, que se realiza, entre otros motivos, con la específica finalidad de que las cifras que se suministran sirvan "para los posibles planes de defensa que se trate de proyectar, tomar como punto de partida el volumen de agua a la que se ha de procurar dar salida en caso de inundación". Cabe recordar que la solvencia de este estudio fue reconocida cuarenta años después de su formulación ${ }^{31}$.

Por tanto, existe una discordancia entre las mediciones efectuadas por la Confederación Hidrográfica del Júcar y la del Servicio de Meteorología Nacional. La pri-

28 Ayuntamiento de Valencia.www.valencia.es.

29 Insausti et al, 1990.

30 García \& Carrasco, 1958, p. 23.La cuenca del río Turia recibió "del orden de 826 millones de metros cúbicos el día 13; si se descuenta un 25 por ciento como desaguada directamente al mar por los barrancos que no afluyen al Turia y otro 25 por ciento detenida en parte por los pantanos de Generalísimo y de Buseo y en parte esparcida por desbordamientos de los cauces afluentes al río principal, quedan 413 millones de metros cúbicos a los que hubiera habido que dar salida el cauce del Turia al ritmo medio de 4.780 metros cúbicos por segundo. Siendo así que el máximo aforo de éste a su paso por la capital se estima en 3.700 metros cúbicos por segundo, queda comprobado con creces (pues la reducción que en este cálculo se ha hecho del volumen total es a todas luces exagerada) que el desbordamiento habría de producirse, máxime si se tiene en cuenta que, por las variaciones de intensidad de las precipitaciones en las veinticuatro horas, el volumen de la avenida hubo de ser en algún momento superior a los 6.000 metros cúbicos por segundo". 31 Pérez Aparisi, 1997, p. 231. El Jefe del Grupo de Predicción para las Comunidades de Valencia, y Murcia del Instituto Nacional de Meteorología califica el estudio de "minucioso, concienzudo, admirable para los medios con que contaban hace 40 años". 
mera ofrece una medición del caudal de $3.700 \mathrm{~m} 3 /$ segundo, mientras que la segunda afirma que en algunos momentos debió de ser superior a $6.000 \mathrm{~m} 3 /$ segundo. El valor del estudio del Servicio Meteorológico goza de un mayor reconocimiento debido a que en él ya se recoge la medición de $3.700 \mathrm{~m} 3 /$ segundo efectuada por la Confederación Hidrográfica que, en realidad, queda rectificada por la de 6.000 m3/s. realizada por el Servicio Meteorológico Nacional.

Con independencia de estos datos incontrovertibles, la propia Confederación Hidrográfica del Júcar, ha subido la estimación hasta 4.400 m3/segundo. Existen otros estudios fundamentados que afirman que el caudal fue muy superior y lo sitúan en $10.000 \mathrm{~m} 3 /$ segundo $^{32}$. A partir de estos datos el Nuevo Cauce fue diseñado para una capacidad de evacuación de $5.000 \mathrm{~m} 3 /$ segundo, lo que tomando como base la cifra de $3.700 \mathrm{~m} 3 / \mathrm{s}$, ofrecía un margen de seguridad de $1.300 \mathrm{~m} 3 / \mathrm{s}$. De todo lo anterior parece fundamentado poner bajo sospecha la evaluación de los 3.700 $\mathrm{m}^{3} / \mathrm{s}$ y reconocer, tal vez, que la avalancha que se produjo fue realmente superior, en cuyo caso, la capacidad de desagüe del nuevo cauce podría ser insuficiente.

Otro factor debe tenerse en cuenta que agrava la situación en relación con la avalancha de 1957, cual es el cambio climático que se ha producido en estos sesenta años y que acentúan la gravedad de la amenaza. Existe consenso científico de que "las condiciones (climáticas) han cambiado o están próximas a cambiar y de que es necesario adoptar medidas para retornar a un estado deseado, para mantenerlo o para alcanzarlo"33.

Como puede verse en el cuadro siguiente, se está produciendo en España un significativo aumento de las temperaturas, una disminución del volumen global de precipitaciones y un aumento de su intensidad. Podría concluirse" ${ }^{\prime 34}$ que los últimos 30 años presentan un período de calentamiento sin precedentes durante los últimos dos milenios. No se tiene memoria de episodios estivales de calor extremo como los vividos en 2003, 2010, 2015, 2016 y 2017. Los últimos veranos han sido los más calurosos de los últimos dos milenios en Europa y particularmente en la zona mediterránea, donde es más probable que se presenten con mayor intensidad y de forma más temprana anomalías climáticas. En el área mediterránea ninguna medida concreta se ha adoptado en razón del cambio climático, al igual que sucede en la mayoría de las ciudades, a excepción de algunos casos paradigmáticos ${ }^{35}$.

32 Sorribes \& Monrabal, 2015, p. 221. La Solución Sur aprobada en el año 1958 por el Consejo de Ministros "consistía en desviar el cauce del Turia construyendo un nuevo canal desde Quart de Poblet hasta Pinedo de 12,6 km de longitud 200 metros de anchura y con capacidad para soportar 10.000 metros por segundo". Aunque el dato de la capacidad de desagüe es erróneo, tal vez el autor se ha dejado llevar por las diversas estimaciones efectuadas con posterioridad en relación con el caudal de la avenida.

33 Magrin et al, 2007: Embid, 2017.

34 Luterbacher et al, 2016.

35 London Climate Partnership, 2006; Revi, 2008; Annals of the New York Academy of Sciences, 2010; Hardoy \& Lankao Romero, 2011; Heinrichs et al., 2011. 


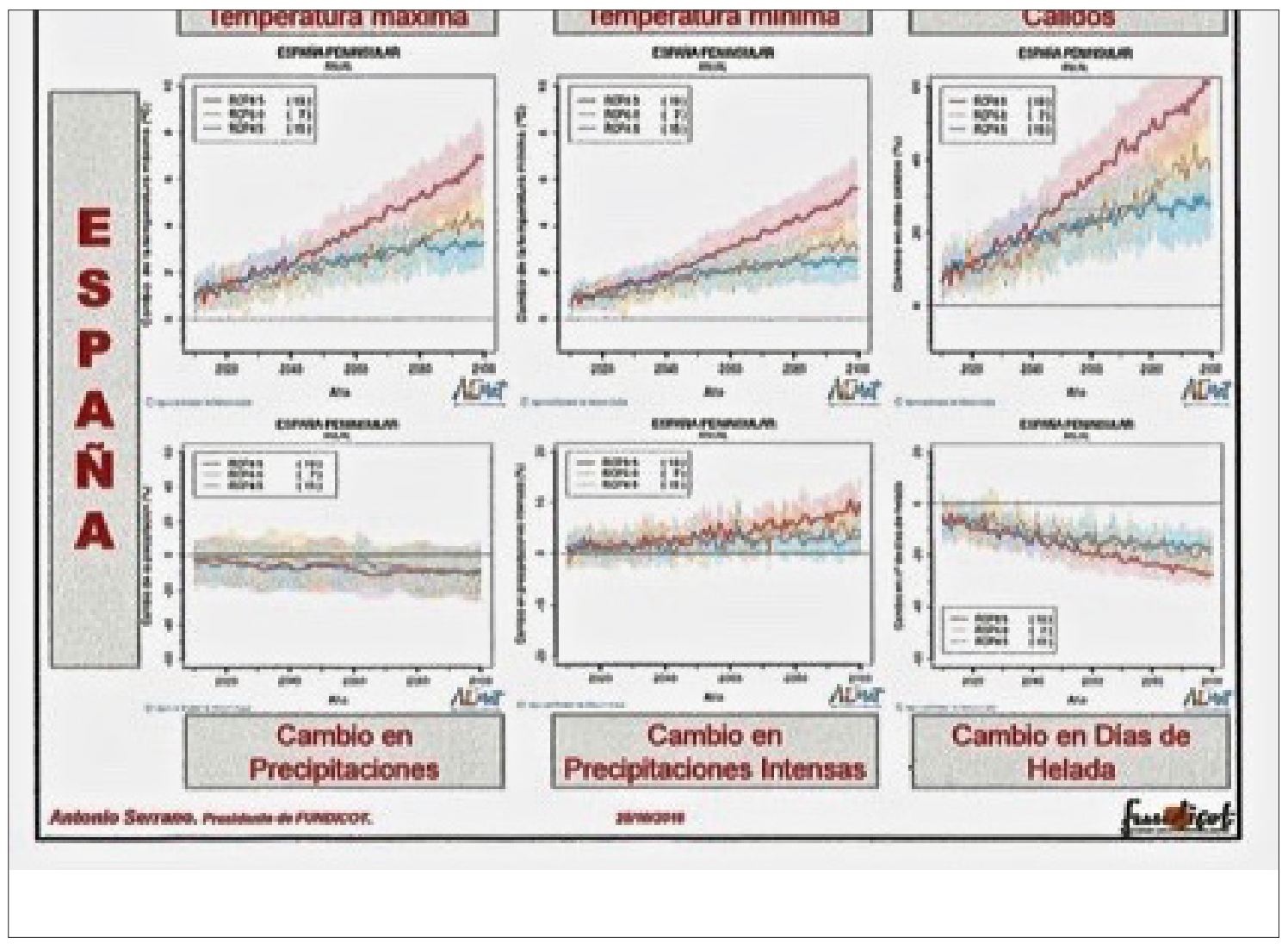

Figura 3. Cambio de temperatura máxima y mínima

Fuente: Antonio Serrano. FUNDICOT (Asociación interprofesional de ordenación del territorio)

En el Plan de Gestión del Riesgo de Inundación ${ }^{36}$, la Confederación Hidrográfica del Júcar reconoce que, al combinar las precipitaciones totales anuales para evaluar cambios en la torrencialidad del clima, aparece una componente creciente en una parte más extensa del territorio, en la que disminuye la precipitación total anual. En esa línea, las previsiones del VI Documento Técnico del IPCC, ponen de manifiesto que en latitudes medias similares a la que ocupa España, indican como probable el aumento de la frecuencia e intensidad de los episodios de precipitación, así como una disminución de valores medios en verano ${ }^{37}$. Esta valoración de las condiciones climáticas y su creciente propensión a episodios que pueden originar situaciones catastróficas forma parte de la tendencia general que se registra en los países de la Unión Europea.

\section{Cambio antrópico y riesgo de inundación}

Es una realidad que el riesgo de inundación, como riesgo natural, se ha visto aumentado por la ocupación urbana en espacios de riesgo, que aumenta el peligro natural pudiendo llegar a considerarse un riesgo o, incluso, catástrofe por esa vulnerabilidad antrópica. Los episodios de inundación responden a tres causas principales: atmosféricas, que aportan el elemento principal, la precipitación abundante

36 Plan de Gestión del Riesgo de Inundación, Demarcación Hidrográfica del Júcar, Valencia 2015, p. 4. 37 Plan de Gestión del Riesgo, p. 5. 
y/o torrencial; geográficas, que favorecen el desarrollo de la crecida fluvial; y antrópicas aumentan la vulnerabilidad y exposición ante los desbordamientos de los ríos $^{38}$. Ha sido generalizado el crecimiento de las superficies urbanizadas a lo largo de la geografía española, crecimiento tanto de viviendas como de infraestructuras que les dan soporte. En este sentido, el Observatorio de la Sostenibilidad en España, en el documento "Cambios de ocupación del suelo en España (p. 345)" afirma que el crecimiento de las superficies artificiales en el período 1987-2000, experimentó un crecimiento medio en España del 25\%, y en concreto, un crecimiento de zonas urbanas en la Comunidad Valenciana de un 30,3\%, siendo uno de los más elevados de España. Así, que "el crecimiento de la urbanización en una década escasa, alcance en las zonas más dinámicas españolas a la mitad de todo lo que se había urbanizado desde los romanos hasta hoy, es un indicador drásticamente expresivo del desbocado cambio de modelo de ocupación del territorio acontecido en los últimos años"39. El cambio antrópico en la cuenca baja del Turia ha contribuido a aumentar la exposición a los peligros naturales, como es el riesgo de inundación, por las actuaciones de urbanización realizadas sobre el territorio. Cuando se producen las lluvias de intensidad moderada entendidas como fenómeno natural, los cauces de los ríos vuelven a recuperar su funcionalidad pasando a transformar estas zonas urbanizadas en zonas de alto riesgo puesto que han sido ocupadas por el ser humano sin tener en cuenta su denominación de zona inundable.

Las nuevas construcciones agravan las potenciales inundaciones por la presión que llevan a cabo en el terreno natural colindante al margen del río Turia impidiendo el flujo libre de las aguas y formando "presas" que agravan el riesgo de inundación. Así, en la cuenca baja del Turia y hasta el embalse de Loriguilla, además de los núcleos de población que lindan con el cauce del río (Valencia, Xirivella, Mislata, Quart de Poblet, Manises, Ribarroja del Turia, Benaguacil, Villamarxant, Pedralba, Bugarra, Gestalgar, La Ermita y Chulilla), han ido apareciendo a lo largo de las últimas décadas urbanizaciones que con toda claridad invaden las áreas inundables: Urbanización La Presa, Urbanización Els Pous de Crisostom, Urbanización Valencia La Vella (Ribarroja del Turia), Urbanización Mulló de Crusa (Villamarxant), entre otras, inexistentes cuando se produjo la riada de 1957.

Estas urbanizaciones se encuentran en las zonas delimitadas como zonas con riesgo de inundación alto según el Plan Especial frente al Riesgo de Inundaciones de la Generalitat Valenciana revisado en el año 2015. En el plan o anterior se pueden observar en color más oscuro, aquellas zonas con riesgo de inundación alto que discurren a lo largo del río Turia.

\section{El escenario a evitar}

En los últimos años se han registrado lluvias en el litoral de la región valenciana que han alcanzado o superado los 300 litros por metro cuadrado en 24 horas. En la figura

38 Olcina, 2008, p. 48. Gil-Guirado, 2017.

39 Roger, 2011, p. 92: Escartin, 2016. 


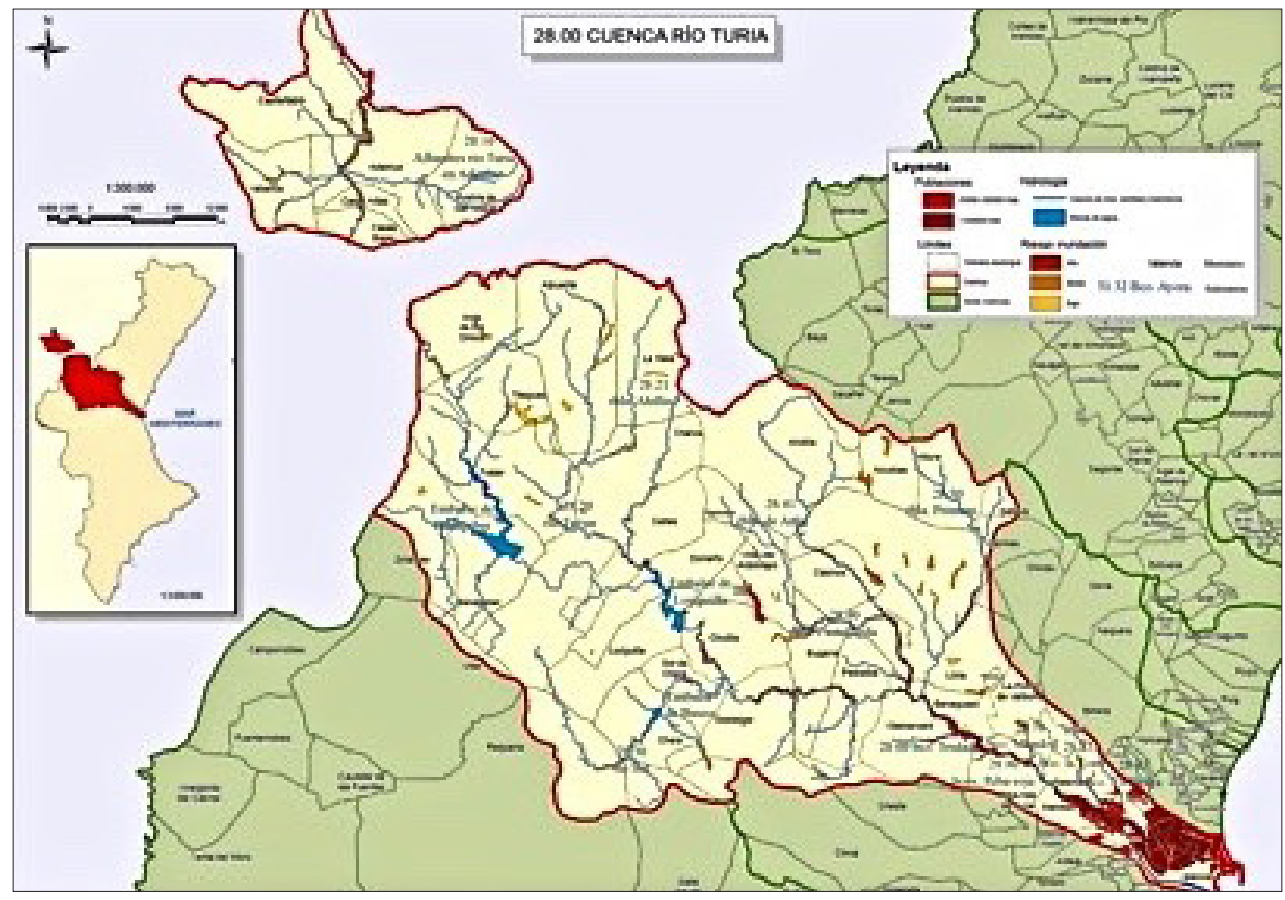

Figura 4: Plano zonas con riesgo de inundación alto según Plan Especial frente al riesgo de inundaciones de la Generalitat Valenciana revisado en el año 2015 Fuente: Plan Especial frente al riesgo de inundaciones de la Generalitat Valenciana, 2015

5 puede observarse un episodio en el que a lo largo del invierno se llega a los $400 \mathrm{l} /$ m2 en un día y otro en el que se llega a los 300 l/m2.

Lo anterior evidencia una situación de riesgo reconocido como "una condición latente o potencial", cuyo "grado depende de la intensidad probable de la amenaza y los niveles de vulnerabilidad existentes" ${ }^{40}$.

Afortunadamente esas precipitaciones no se han producido en la cuenca baja del río Turia. Si esto llegara a suceder en el futuro, los $2.124 \mathrm{Km} 2$ de cuenca baja del río Turia, podrían llegar a recibir $600 \mathrm{Hm} 3$ de precipitación. Suponiendo un coeficiente global de escorrentía de 0,65 para toda la cuenca baja del río, su cauce tendría que desaguar un caudal superior a $400 \mathrm{Hm} 3$ en 24 horas ya que, como se ha dicho, no existe ningún embalse regulador en la cuenca baja. Esto supondría un caudal sostenido de al menos $4630 \mathrm{~m} 3 / \mathrm{segundo}$ durante 24 horas, pero como las riadas suelen desarrollarse por avenidas se podrían alcanzar máximos de $6.000 \mathrm{~m} 3 / \mathrm{segun}$ do.

Además, como quiera que las lluvias torrenciales vienen acompañadas de fuertes temporales marítimos, el desagüe no es un flujo continuo, ya que éste sólo se produce según los flujos y reflujos del oleaje. En este caso la mota ubicada en el origen del desvío del río por el nuevo cauce podría ser rebasada y las aguas avanzarían hacia los túneles del metro y del ferrocarril invadiendo el antiguo cauce, el cual, a diferencia del año 1957, no es un cauce libre ya que en él se han construido diversas e importantes instalaciones como son la Ciudad de las Ciencias y de las Artes y numerosos equipamientos deportivos y recreativos que propiciarían el efecto de

40 Lavell, 1996, p. 21-60. 


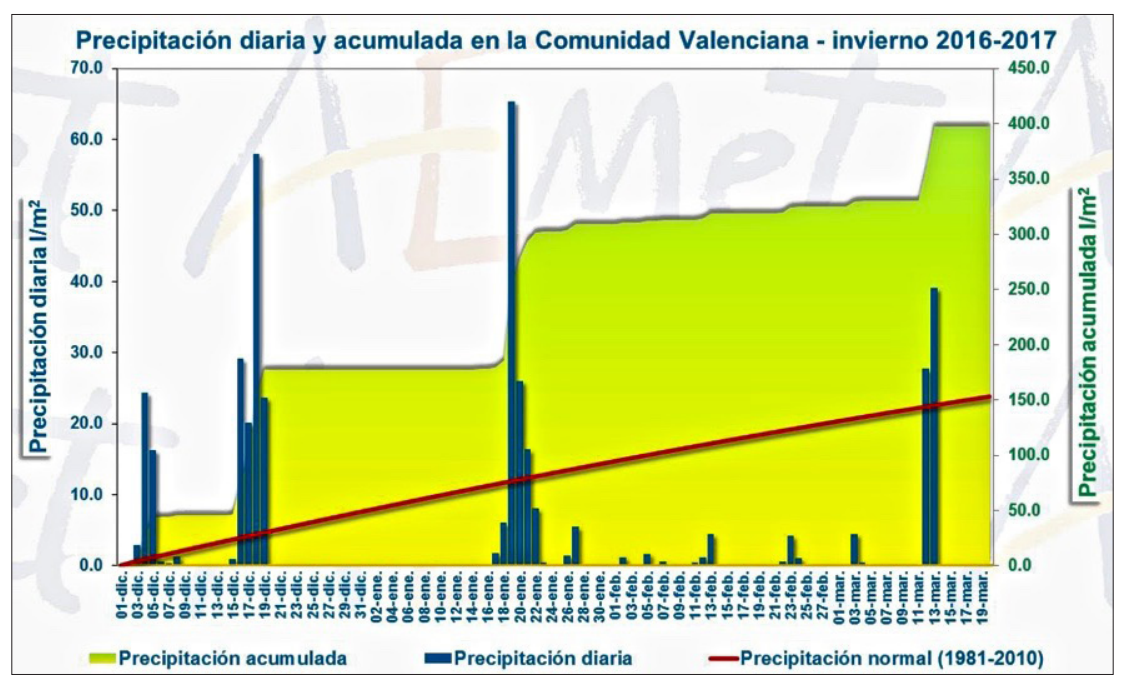

Figura 5: Precipitación diaria y acumulada en la Comunidad Valenciana-invierno 2016-2017

Fuente: AEMET (Agencia estatal de meteorología - Gobierno de España)

embalse. El hipotético escenario, aunque no descartable, podría consistir en el desbordamiento del nuevo cauce con efectos sobre el área urbana y el embalsamiento del antiguo, con tal nivel que alcanzara también a la propia ciudad. Lo cierto que el nuevo cauce del Turia, obra de la que depende la seguridad de la ciudad de Valencia frente a las grandes avenidas, todavía no ha sido puesta a prueba con una de esas dos grandes avalanchas que se suceden cada siglo, como también sucede con otras realizaciones que en España tienen parecido carácter ${ }^{41}$.

\section{La necesaria adopción de medidas frente a futuras amenazas}

De lo anterior se deduce la ausencia de una seguridad plena frente al fenómeno de la "gota fría", riesgo agudizado, además, por el cambio climático y el cambio antrópico realizado en la cuenca baja del río. La propia Administración Pública es consciente de este potencial riesgo y se han diseñado diversas actuaciones que, lamentablemente, no se han llevado a la práctica. Así, en los Presupuestos Generales del Estado de 2008, existía una partida de 18 millones de euros destinada al recrecimiento de las paredes laterales del cauce con el fin de aumentar su capacidad de desagüe. Por otra parte, la entidad estatal AQUAMED auspició un estudio que obra en poder de la Confederación Hidrográfica del Júcar (Gabinete de Planificación) que contiene las siguientes medidas:

1.- Excavación de un cauce secundario en el actual cauce con un coste de 17 millones de euros.

2.- Colocación de prefabricados New Jersey de altura de 0,80 metros recreciendo los cajeros actuales con un coste de 10 millones de euros. Con ello la capacidad de desagüe se aumentaría en un cincuenta por ciento.

41 Pérez-Morales, Gil-Guirado \& Olcina, 2016, p. 234. 


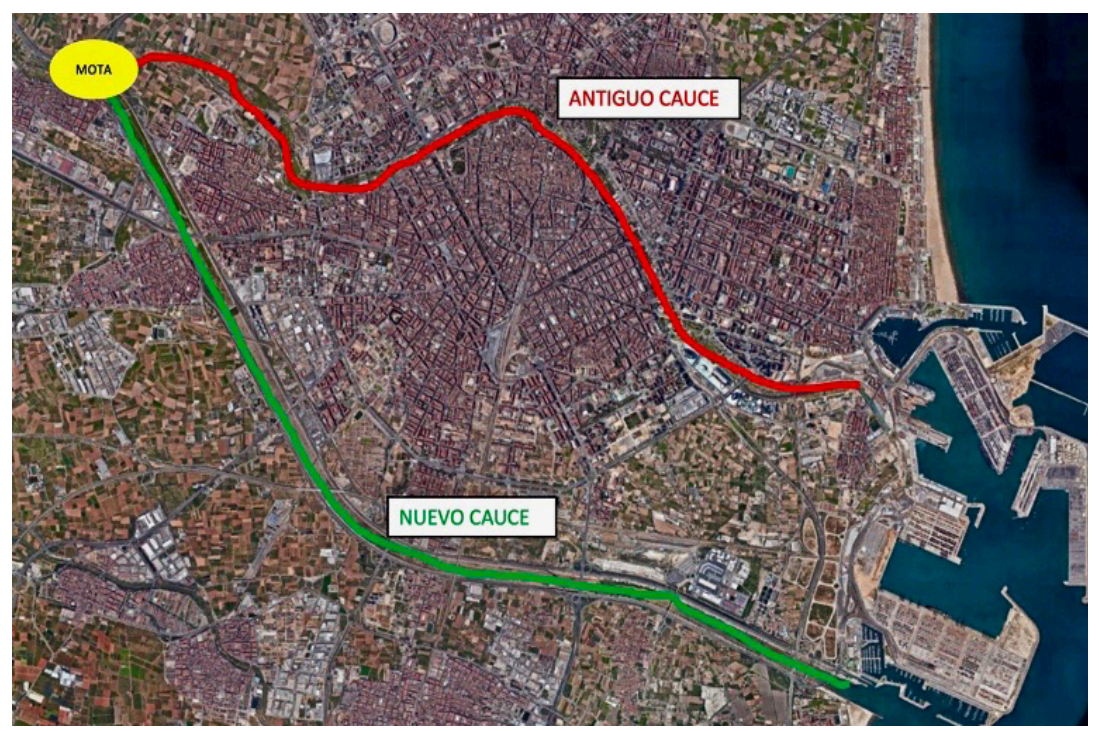

Figura 6: Situación del antiguo y nuevo cauce del Río Turia. Mota de Quart

Fuente: Elaboración propia

La iniciativa de recrecimiento del cauce con prefabricados del tipo New Jersey también fue expuesta públicamente por el coautor de este artículo en una conferencia impartida el día 6 de mayo de 2014 en el Ateneo de la Ciudad de Valencia ${ }^{42}$.

Con las anteriores medidas estructurales diseñadas y propuestas por la administración pública y no ejecutadas, la capacidad de desagüe aumentaría en la proporción citada, suficiente para evacuar los caudales de máxima crecida que se con-

Cuadro 1. Proyecto informativo de acondicionamiento del nuevo cauce del río Turia. 2007

\begin{tabular}{llrr}
\hline Capítulo & Resumen & Importe & $\%$ \\
\hline SUBOBRA.- 01 & Actuaciones en el nuevo cauce & $20.852 .022,77$ & 95,61 \\
Cap.- 01.01 & $\begin{array}{l}\text { NC1. Nueva rasante hidráulica azud } \\
\text { repartiment-azud intermedio }\end{array}$ & $13.857 .740,26$ & \\
Cap. 01.02 & NC2. Demolición azud intermedio & $2.088 .952,48$ & \\
Cap. 01.03 & NC3. Protección en márgenes & $4.055 .120,87$ & \\
Cap. 01.04 & NC4. Nueva rasante hidráulica zona & $850.209,16$ & \\
SUBOBRA.- 02 & Sestructura línea l metro & $601.267,80$ & 2,76 \\
SUBOBRA.- 03 & Servicios afectados & $85.310,81$ & 0,39 \\
SUBOBRA.- 04 & Medidas correctoras & $270.208,24$ & 1,24 \\
\hline & Estudio de seguridad y salud & $\mathbf{2 1 . 8 0 8 . 8 0 9 , 6 2}$ & \\
\hline
\end{tabular}

Fuente: Entidad estatal AQUAMED

42 Fullana, 2014. 
tienen en el Informe del Servicio Meteorológico Nacional de 1958, anteriormente referido, que fundadamente evalúa la riada con valores superiores a los emitidas por la Confederación Hidrográfica. Junto a lo anterior, resulta de capital importancia el reforzamiento de la mota de tierra y hormigón situada en la población de Quart de Poblet que constituye el punto de desvío de las aguas para su encauzamiento por el nuevo cajero. De rebasarse esta mota el agua fluiría por el cauce antiguo que atraviesa la ciudad.

Como se ha advertido anteriormente, los tramos altos y medio del río Turia están regulados por importantes embalses, no así el tramo bajo, siendo que alberga una peligrosidad extrema. Por ello el Plan Sur incorporó a su estrategia la realización de la presa de Vilamarchante, proyecto que en el año 2001 fue incorporado al Plan Hidrológico Nacional ${ }^{43}$. El proyecto, al igual que las anteriores iniciativas, no se ha ejecutado. La realidad es que, aunque siga figurando en el Plan Hidrológico Nacional, lo cierto es que existe un convencimiento generalizado de abandono del citado proyecto, en razón de la peligrosidad que supondría para la propia ciudad de Valencia en caso de ruptura de la presa.

Junto a las anteriores medidas previstas de carácter estructural - que hacemos nuestras salvo la referente a la presa de Vilamarchante-, por nuestra parte apuntamos otras de carácter estratégico que sería preciso adoptar, a saber:

1- Consolidación de un sistema de alerta temprana compuesto por una red mallada de estaciones meteorológicas, aforos de cauces y videocámaras por la cuenca baja del Turia con aportación continua de datos pluviohidrológicos en tiempo real,

2- La adopción de un enfoque integrador y potenciador de las actuaciones de las distintas administraciones públicas en base a los principios de cautela, prevención y cooperación,

3- La potenciación de la colaboración entre la administración pública y los operadores privados en la protección de las infraestructuras críticas.

4- Adopción de planes de preparación y respuesta ciudadana que promuevan una cultura de resiliencia ante emergencias.

5- Elaboración de modelos informáticos y simulaciones por ordenador de distintas hipótesis de crecidas del río Turia y sus efectos, tanto en las zonas urbanas como en la totalidad de la cuenca para optimizar los planes de evacuación y emergencia.

6- Actualización de planes de protección civil y emergencia para los diferentes sectores de población, en especial los que presentan mayores dificultades de evacuación y creación de una Unidad de Documentación de Catástrofes, la cual debería estar dotada de medios suficientes y autonomía funcional para la recopilación y sistematización de todo tipo de información que serviría de base para adoptar las estrategias de protección.

La implementación de todas estas medidas otorgaría una seguridad frente a la amenaza de nuevas inundaciones, erradicando los riesgos que la propia administración publica no deja de reconocer.

43 Ley 10/2001, de 5 de julio, del Plan Hidrológico Nacional (BOE-A-2001-130429): ANEXO IV Actuaciones prioritarias y urgentes en las cuencas mediterráneas: en la cuenca hidrográfica del Júcar: Art. 3.3. Actuaciones en mejora de la calidad del agua, prevención de inundaciones y restauración ambiental: b) Presa de Vilamarchante. 


\section{Gobernanza y planificación territorial frente al riesgo hídrico}

La Unión Europea en los últimos 15 años viene prestando una creciente atención al fenómeno de los desastres naturales y particularmente al riesgo de inundación, lo que se ha manifestado en una importante legislación que debe ser adoptada por los estados miembros.

Este grave riesgo ha dado lugar a que las instancias de la Unión Europea hayan elaborado un cuerpo doctrinal que ha inspirado un panel legislativo de notable importancia. En este sentido la Directiva 2007/60/CE del Parlamento Europeo y del Consejo, de 23 de octubre, relativa a la evaluación y gestión de los riesgos de inundación ("Directiva de inundaciones"), fue incorporada al derecho interno español por el Real Decreto 903/2010, de 9 de julio, de evaluación y gestión de riesgos de inundación. Con esta Directiva, por primera vez la Unión Europea (UE) establece un marco común para evaluar, cartografiar y planificar la reducción del riesgo de inundación en Europa, abarcando todo tipo de inundaciones y distinguiendo tres tipologías esenciales: Pluviales: derivadas de importantes precipitaciones in situ que resultan ser las más frecuentes en España. Inundaciones fluviales: derivadas del desbordamiento de cauces. Marinas: derivadas de temporales marinos en la costa. La definición del término inundación recogido en la propia Directiva coincide en lo sustancial con la de la Directriz Básica de Protección Civil del Gobierno de España ${ }^{44}$.

En el marco normativo de la UE se han configurado importantes principios que habrán de inspirar las regulaciones de los estados miembros en materia de gestión y defensa frente al riego de inundación. En primer lugar el principio de prevención que es uno de los pilares básicos de la política medioambiental europea que ya figuraba recogido en los arts. 191 y siguientes del Tratado de Funcionamiento de la Unión Europea (TFUE), firmado en Roma en 1957 como Tratado constitutivo de la Comunidad Económica Europea. Se formula de modo que "El principio de acción preventiva implica la posibilidad de adoptar medidas de protección del medio ambiente aun antes de que se haya producido la lesión del mismo, siempre que se constate científicamente la existencia de un peligro real de deterioro ambiental". Se añaden los principios de cautela y de rectificación con el axioma de "quien contamina paga" sancionado por la Organización para la Cooperación y el Desarrollo Económicos (OCDE), dentro del cuerpo de "Principios directores referentes a los aspectos económicos de las políticas ambientales en su perspectiva internacional" ${ }^{45}$.

El principio de cautela, también conocido como el principio de precaución, introducido por el Tratado de Maastricht ${ }^{46}$ refuerza el principio de acción preventiva, al permitir la actuación en aras de la reducción de los posibles riesgos ambientales, sin necesidad de que exista una plena certeza científica. La configuración de este principio puede considerarse la más importante y novedosa aportación en aras de resolver o superar las frecuentes situaciones de incertidumbre que al Derecho Ambiental

44 Menéndez, 2017.

45 Martín, 1991, p.212.

46 Betancor, 2004, p. 268. 


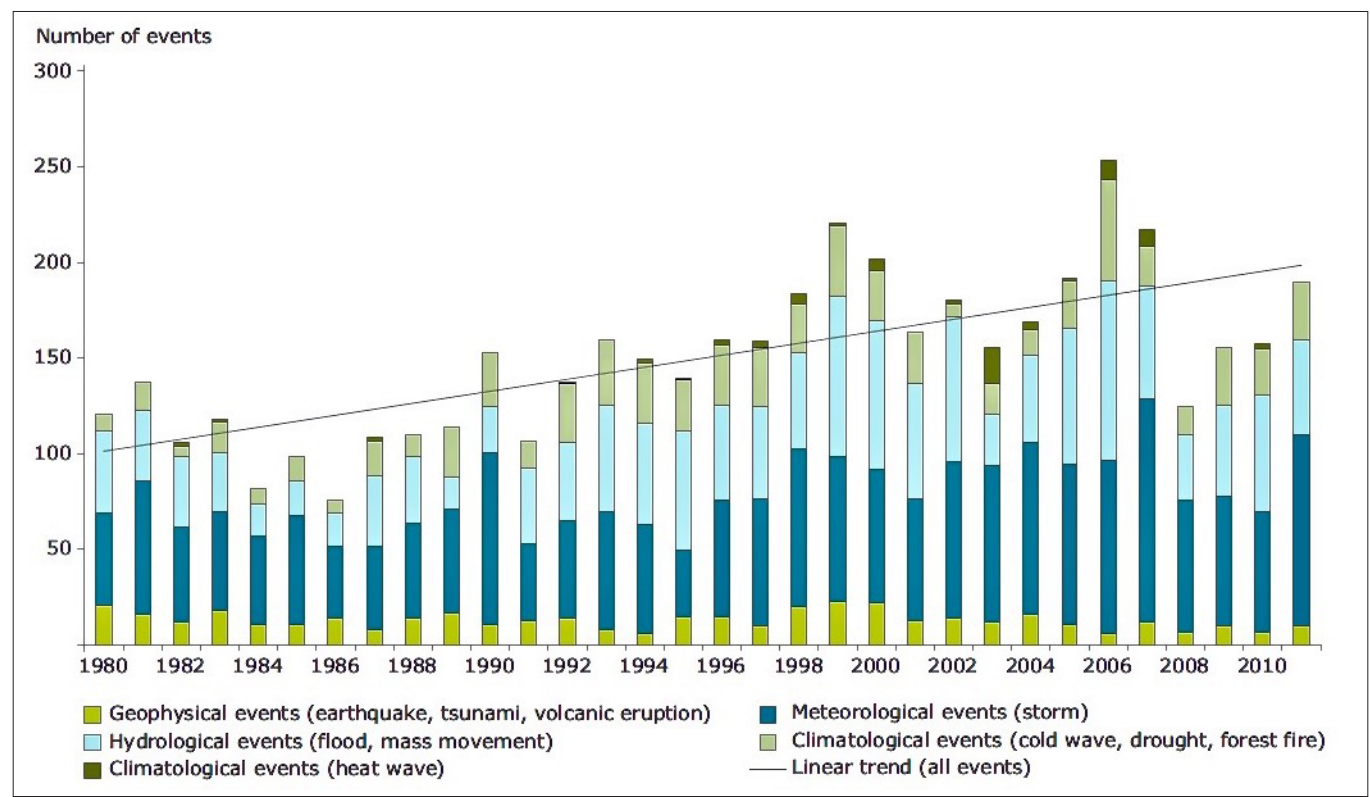

Figura 7: Desastres naturales en estados miembros de la unión europea en el período $1980-2011$

Fuente: Agencia Europea de Medio Ambiente

se le plantean. En efecto, la adopción de medidas preventivas puede llevar consigo la ejecución de proyectos que supongan cuantiosas inversiones y han de estar acogidas por un marco legislativo que les dé plena legitimidad. Puede decirse que este término está ya plenamente arraigado en la legislación y práctica jurídica, adoptado por los tribunales ${ }^{47}$.

Por lo que se refiere a la ciudad de Valencia, encontramos un significativo precedente histórico en la aplicación de este principio con motivo de los gravísimos daños que infligió a la ciudad la catastrófica riada del día 20 de octubre de 1589. En efecto, conocedor el Rey Felipe II de los daños causados, desde el Palacio de El Escorial emite la transcendental Carta Real de 29 de agosto de 1590, en virtud de la cual se exhorta a las autoridades locales a que "con cuidado extraordinario se examinasen los medios que podrían ser oportunos para precaver iguales acontecimientos y que, desde luego, se pusieran en ejecución" ${ }^{48}$.

En el marco normativo español la expresión "zonas inundables" aparece en la Ley de Aguas de 1985 (art. 11.), que faculta al Gobierno de la Nación y a los Gobiernos autonómicos para imponer limitaciones en el uso de dichas zonas ${ }^{49}$. El vigente Real Decreto Legislativo 1/2001, de 20 de julio, por el que se aprueba el Texto Refundido de la Ley de Aguas (TRLA) presta una atención limitada al problema de las zonas inundables y aún menos a las específicas fórmulas e instrumentos de valoración y gestión de este riesgo $0^{50}$.

47 Esteve, 2005, p.57.

48 Archivo Municipal de Valencia (AMV), 1725.

49 Olcina, 1995.

50 Mellado, 2011. 
Una importante dificultad que entorpece la adopción de medidas concretas ante el riesgo de inundación, se deriva del peculiar cuadro normativo español en el que las competencias en la materia son compartidas por muy diversas administraciones de diversos niveles, desde el nivel local en la elaboración del planeamiento urbanístico y protección civil, al autonómico, en materia de ordenación del territorio, protección civil y gestión del dominio público hidráulico ${ }^{51}$ en las cuencas intracomunitarias y, por fin, el nivel estatal, en relación con la protección civil, la gestión del dominio público hidráulico en las cuencas intercomunitarias y la gestión del dominio público marítimo terrestre en las inundaciones causadas en las zonas de transición y las debidas a la elevación del nivel del mar. A partir del marco normativo y competencial referido, analizamos seguidamente el tratamiento que el planeamiento territorial ofrece en relación con el riesgo hídrico que, a nuestro juicio, sigue afectando al área en la que se enclava la ciudad de Valencia. Los planes que analizamos se corresponden con las competencias que ostentan las diferentes administraciones.

En primer lugar, los planes emanados de la administración estatal. En este sentido, la modificación del Reglamento del Dominio Público Hidráulico (RPDH), aprobada por el Real Decreto 638/2016, de 9 de diciembre de 2016, ha sido completado acertadamente en septiembre de 2017 por una Guía técnica de apoyo en materia de limitaciones a los usos del suelo en las zonas inundables de origen fluvial ${ }^{52}$, que recogen los principales aspectos a tener en cuenta en la aplicación del RDPH, así como el encaje general del mismo en la aplicación de la Directiva de Inundaciones de la UE y en los trabajos que derivados de ella se están realizando, siendo de gran utilidad para los operadores que intervienen en la planificación territorial y urbanística, por la tan demandada unificación de criterios entre las distintas administraciones implicadas en materia de gestión y defensa de este riesgo.

Según la citada Guía Técnica, la valoración del riesgo de inundación de la cuenca baja del río Turia figura en los siguientes planos e información complementaria.

La cartografía incluida en este servicio contiene las áreas definidas como Áreas con Riesgo Potencial Significativo de Inundación (ARPSIS), obtenidas a partir de la evaluación preliminar del riesgo de inundación realizada por las autoridades competentes en materia de aguas, costas y protección civil.

Se definen como ARPSIS a aquellas zonas de los Estados miembros de la UE para las cuales se ha llegado a la conclusión de que existe un riesgo potencial de inundación significativo, o bien en las cuales la materialización de tal riesgo pueda considerarse probable como resultado de los trabajos de Evaluación Preliminar del Riesgo de Inundación (EPRI), dando cumplimiento al art. 5 del Real Decreto 903/2010, de 9 de julio, de evaluación y gestión de riesgos de inundación. En la figura anterior se

51 García, 2003.

52 MAPAMA, Guía técnica de apoyo a la aplicación del reglamento del dominio público hidráulico en las limitaciones a los usos del suelo en las zonas inundables de origen fluvial. 


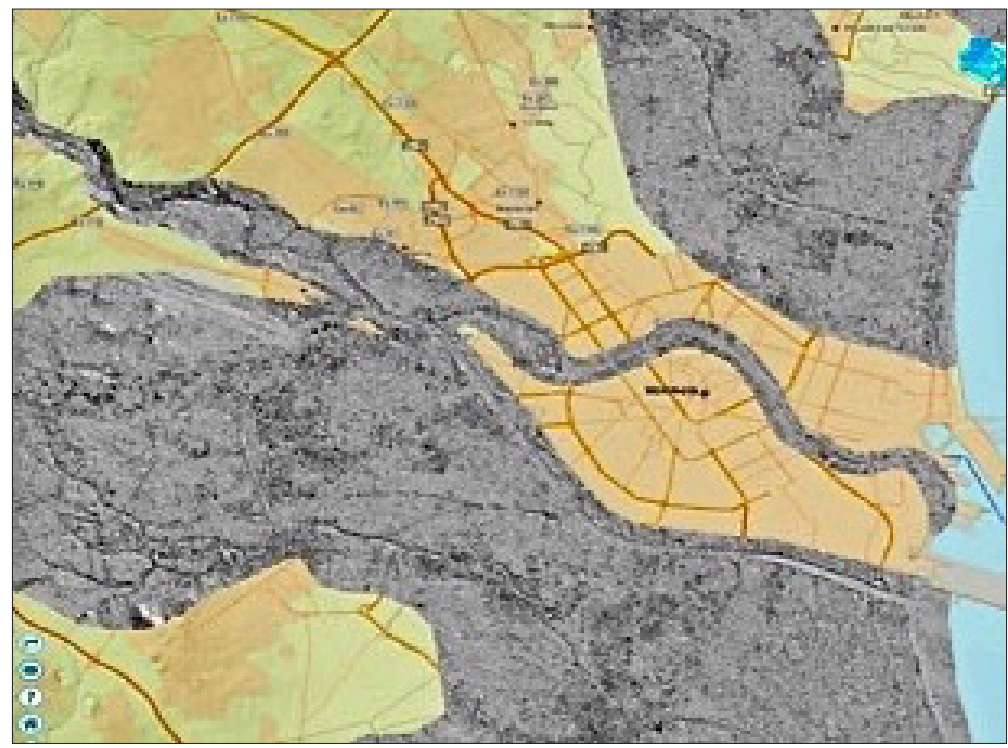

Figura 8: Áreas con riesgo potencial significativo de inundación (ARPIS)

Fuente: Ministerio de agricultura y pesca, alimentación y medio ambiente. España, 2018

observa la zona con más intensidad de color determinada como ARSIPS en la ciudad de Valencia y área metropolitana.

El siguiente instrumento emanado de la administración estatal (Confederación Hidrográfica del Júcar) es el Plan de gestión del riesgo de inundación de la Cuenca Hidrográfica del Júcar de 2015.

Una de las nuevas herramientas clave para luchar contra este riesgo prevista en la Directiva 2007/60 de la Unión Europea, es la elaboración, aprobación e implantación de los planes de gestión del riesgo de inundación (PGRI) regulados en el Real Decreto 903/2010. El objetivo principal de estos planes de gestión debe ser, para aquellas zonas determinadas en la evaluación preliminar del riesgo, conseguir que no se incremente el riesgo de inundación actualmente existente y que, en lo posible, se reduzca a través de los distintos programas de actuación, que deberán considerar todos los aspectos de la gestión del riesgo, centrándose en la prevención, protección y preparación, incluidos la previsión de inundaciones y los sistemas de alerta temprana, y considerando las características de la cuenca o subcuenca hidrográfica referidas, lo cual adquiere más importancia al considerar los posibles efectos del cambio climático ${ }^{53}$.

Se destaca la relevancia de gestión del riesgo de estos planes en su relación con los planes territoriales y urbanísticos, ya que en la ordenación que hagan de los usos del suelo no podrán incluir determinaciones que no sean compatibles con el contenido de los planes de gestión del riesgo de inundación, y reconocerán el carácter rural de los suelos en los que concurran dichos riesgos de inundación o de otros accidentes graves, según el art. 15.1 Real Decreto 903/2010. No obstante, como los PGRI no tienen carácter normativo, las limitaciones al uso del suelo en las zonas

53 González, 2008: Cardona et al, 2012: Thorndycraft et al, 2003. 


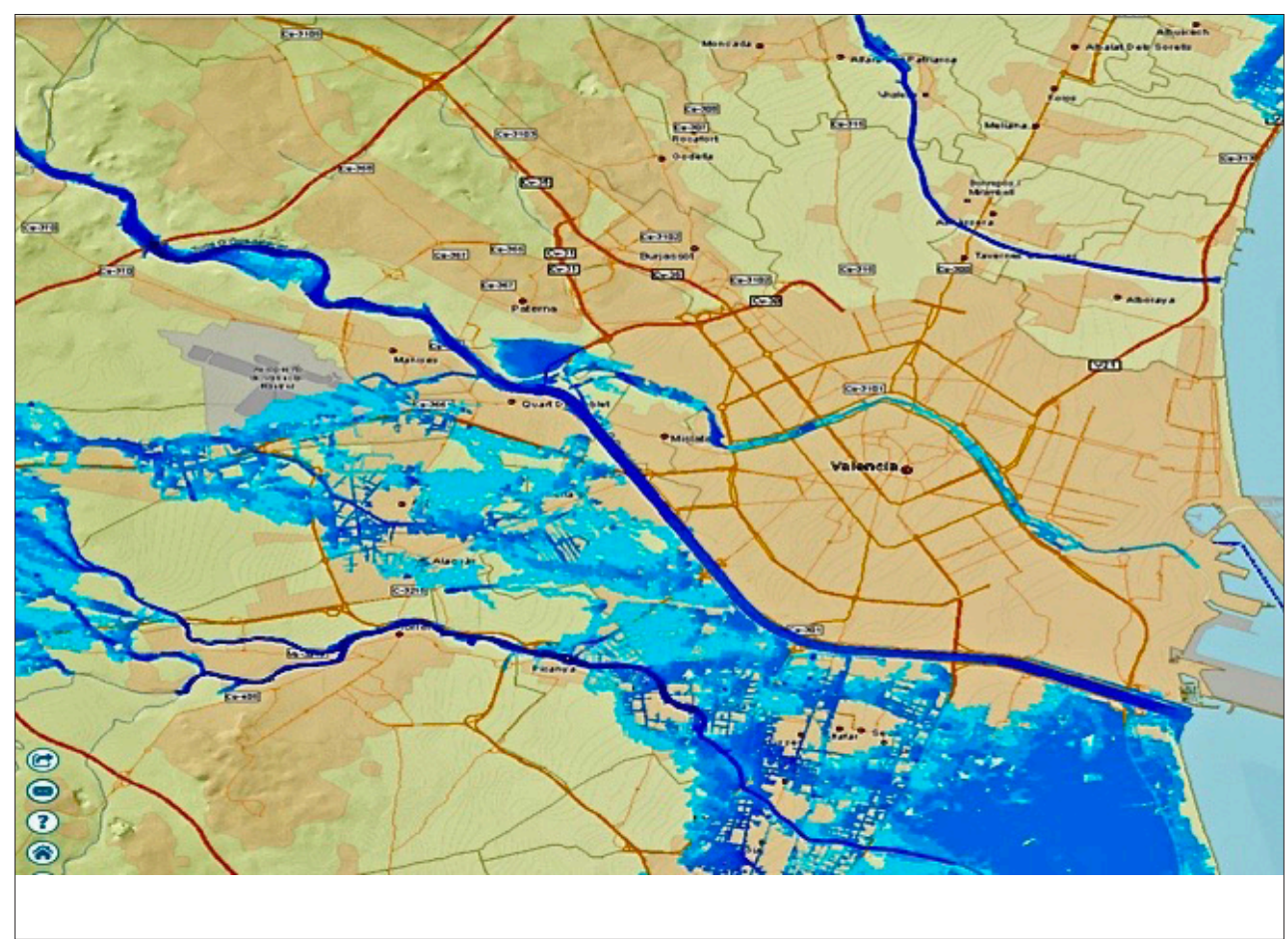

Figura 9: Mapa por inundación fluvial t=500 años

Antiguo cauce: Posible inundación a cotas muy bajas con un período de retorno de 500 años (color azul claro)

Nuevo cauce: Cotas mucho más altas llegando hasta los 8 metros (color azul oscuro)

Fuente: Ministerio de agricultura y pesca, alimentación y medio ambiente. España, 2018

inundables no se establecen en estos planes sino en el Reglamento del Dominio Público Hidráulico y en los planes hidrológicos de cada demarcación.

\section{El Plan de gestión del riesgo de inundaciones de la Cuenca Hidrográfica del Júcar}

Con referencia al río Turia, entre las medidas estructurales (encauzamientos, motas, diques, etc.) que implican intervenciones físicas en los cauces, aguas costeras y áreas propensas a inundaciones para el período 2016-2021, se prevén 5 actuaciones en el Bajo Turia en el área metropolitana de Valencia, pero no en la propia ciudad de Valencia.

Aunque los citados planes de gestión han supuesto un avance significativo en la gestión de los usos de suelo en zonas inundables, sin embargo, la normativa de estos planes sobre la regulación de usos del suelo para cada una de las Demarcaciones Hidrográficas deja mucho que desear por distintos motivos. En primer lugar, porque no se ha adoptado de manera coordinada y concertada con las Comunidades Autónomas competentes en materia de ordenación del territorio, urbanismo ${ }^{54} \mathrm{y}$ gestión del medio ambiente, algunas de las cuales ya disponían de instrumentos de regulación más detallados y efectivos (por ejemplo, la Comunidad Valenciana ya existía el Plan de Acción Territorial ante el Riesgo de Inundación (PATRICOVA), 
cuya excelencia fue reconocida con una distinción otorgada por el propio Ministerio de Medio Ambiente). En segundo lugar, porque estos planes han carecido de la imprescindible homogeneidad normativa para cada una de las cuencas, con diferencias difícilmente aceptables ${ }^{55}$.

En este plan, la cuenca baja del Turia que sufrió la catástrofe de 1957 se sigue considerando de gran peligrosidad, de conformidad con los datos obtenidos del Plan de Gestión de Riesgos de Inundaciones de la Confederación Hidrográfica del Júcar del 2015, en el cual, la cuenca del bajo Turia tiene valores muy altos tanto en peligrosidad como en riesgo ${ }^{56}$, solo superadas por las Áreas de Riesgo Potencial Significativo (APRS) 0020 (Barranco del Puig, Cañada del Molinar y Barranco de Bords) y 0011

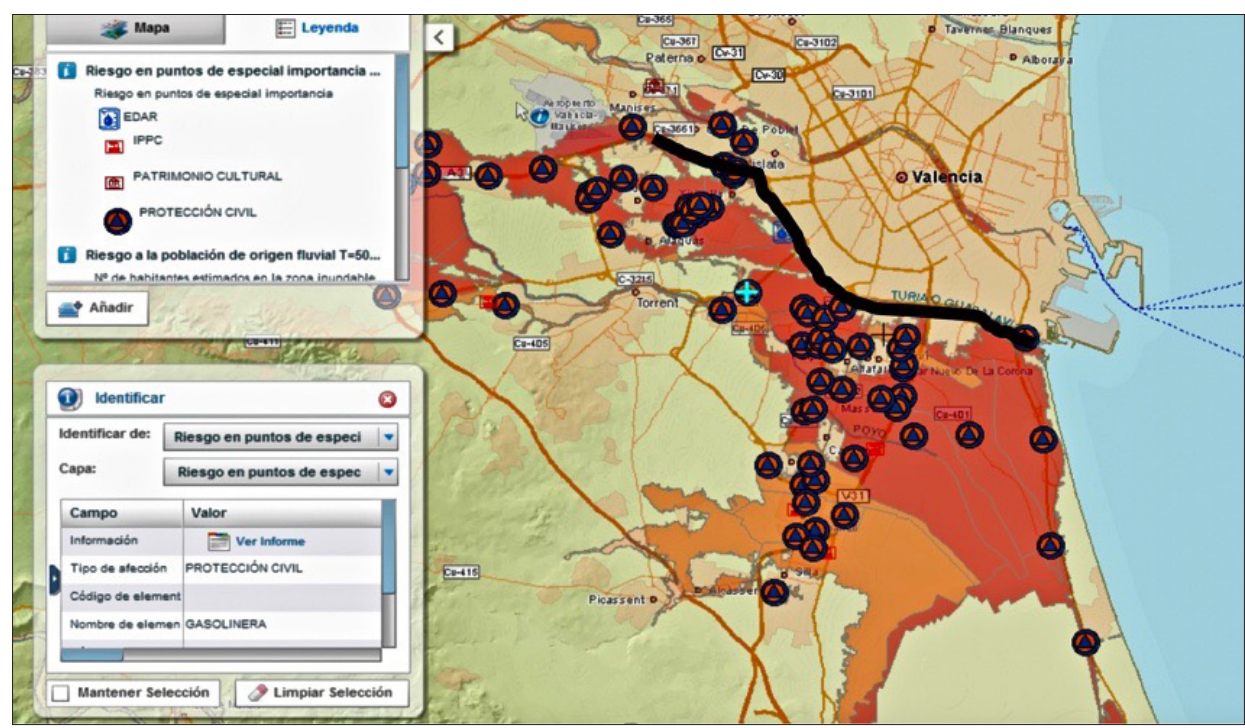

Figura 10: Plan de gestión de riesgo de inundaciones. mapas de riesgo: población afectada y puntos de especial importancia. Imagen visor SNCZI Fuente: Confederación hidrográfica del Júcar 2015

(Rambla Gallinera y Marjal de Pego $)^{57}$. Esta Valoración queda precisada territorialmente por el correspondiente plano que vemos en la Figura 10.

Puede observarse que el área de gran peligrosidad y riesgo queda delimitada de modo nítido por su parte norte por una línea bien definida que es justamente el nuevo cauce del Turia que deja a salvo la ciudad de Valencia. Esta conclusión se obtiene a partir de la supuesta suficiencia del nuevo cauce para evacuar las precipitaciones futuras, conclusión que, como ya se ha dicho, a nosotros nos ofrece

55 Serrano, 2017.

56 ARPSI ES080_ARPS_22, Bajo Turia: Valor de peligrosidad 3,6; Valor de riesgo: 4,4.

57 Áreas de Riesgo Potencial Significativo (APRS): Zonas para las cuales existe un riesgo potencial de inundación en base al estudio de la información disponible sobre inundaciones históricas, estudios de zonas inundables, impacto del cambio climático, planes de protección civil, ocupación actual del suelo, así como las infraestructuras de protección frente a inundaciones existentes. Posteriormente se analizan los baremos de riesgo que permiten valorar los daños identificados y establecer los umbrales que definen los límites del concepto de "riesgo potencial significativo", con el objeto de identificar las áreas de riesgo potencial significativo de inundación (ARPSIs). 
fundados reparos. A pesar de la presunta suficiencia de la infraestructura, el Plan de Gestión de Riesgos, recomienda como medidas a adoptar la construcción de la presa de Villamarchante, proyecto que, como se ha dicho anteriormente, ha sido sometido a nuevas reflexiones, según las cuales se desaconseja su construcción por la gravísima amenaza que supondría para la ciudad ante una posible ruptura, máxime cuando la ejecución de las medidas que se proponen en este trabajo, conjuran definitivamente el riesgo de inundación de la ciudad, según nuestra opinión.

Pasamos seguidamente al análisis de la planificación proveniente del siguiente nivel, esto es, el autonómico o regional. La Comunidad Valenciana fue pionera en regular el riesgo de inundación mediante un instrumento de ordenación territorial supramunicipal, de carácter sectorial denominado Plan de Acción Territorial de Riesgo de Inundación de la Comunidad Valenciana (PATRICOVA), aprobado por Acuerdo del Consell de 28 de enero de $2003^{58}$, derogado por el vigente Decreto 201/2015, de 29 de octubre, del Consell ${ }^{59}$, adaptado a la Directiva 2007/60/CE y al RD 903/2010. Por tanto, la problemática sobre la que actúa este plan es el riesgo de inundación a escala regional en la Comunidad Valenciana.

La aprobación de este plan territorial debe relacionarse con la Orden de 8 de marzo de 1999 relativa a la necesaria observancia de la cartografía de riesgo de inundación ${ }^{60}$. El PATRICOVA se redactó conforme a lo dispuesto en la derogada Ley de Ordenación del Territorio de la Comunidad Valenciana de 1989, y tiene naturaleza vinculante para todos los instrumentos de ordenación urbanística o territorial e incide, entre otras cuestiones, en la clasificación del suelo en cuanto que el dominio público hidráulico y las zonas delimitadas como de riesgo de inundación grado l, deben ser clasificadas como suelo no urbanizable de especial protección ${ }^{61}$.

Este plan regula que los estudios de inundabilidad son imprescindibles para admitir decisiones de planeamiento que se aparten de las determinaciones contenidas en los documentos de carácter vinculante del PATRICOVA (art. 16), que serán aprobados por la Consejería competente en materia de ordenación del territorio previo informe del organismo de cuenca (Confederación Hidrográfica del Júcar). Este in-

58 Diario Oficial de la Comunidad Valenciana [DOCV], núm. 4429, de 30 de enero de 2003.

59 DOCV núm. 7649, de 3 de noviembre de 2015. Doménech, 2017.

60 Orden del Conseller de Obras Públicas, Urbanismo y Transportes, de 8 de marzo de 1999, por la que se declaran de necesaria observancia, en la redacción de los planes urbanísticos o territoriales que se formulen en el ámbito de la Comunidad Valenciana, determinadas cartografías temáticas y estudios integrantes del sistema de información territorial. Entre ellas se encuentra la cartografía sobre delimitación de riesgo de inundaciones a escala regional en la Comunidad Valenciana, que delimita a escala 1:50.000 las zonas de nuestro territorio sometidas a riesgo de inundación apreciable. PATRICOVA, Memoria, p. 58.

El propio Acuerdo de 28 de enero de 2003 por el que se aprueba el PATRICOVA, en el Antecedente Primero dice que por Orden de 28 de marzo de 1999 se "declaró la necesaria observancia en la redacción de los planes urbanísticos o territoriales que se formulasen en las Comunidad Valenciana, la Cartografía Temática publicada por dicha Consellería sobre `Delimitación del riesgo de inundación a escala regional en la Comunidad Valenciana' que ilustraba y delimitaba las zonas de nuestro territorio sometidas a riesgo de inundación apreciable".

61 Romero, 2008, p. 27. 
forme de aprobación tendrá carácter preceptivo y determinante (art. 18). Además, el art. 20 establece:

Los Planes de Acción Territorial, los Planes Generales y sus instrumentos de desarrollo modificativos deberán analizar las condiciones de drenaje superficial del territorio, tanto de las aguas caídas en su ámbito de actuación como las de las cuencas vertientes que le afecten.

Y establece cuál debe ser el contenido de la parte informativa: dominio público hidráulico y servidumbres, zonas con riesgo de inundación, cauces, conos de inundación, etc.

A efectos del PATRICOVA se consideran municipios con elevado riesgo de inundación aquellos en los que, al menos, las dos terceras partes de su término municipal están afectadas por el riesgo, o bien aquellos otros que, aun no cumpliendo la condición anterior, tienen grandes limitaciones para orientar sus futuros desarrollos hacia zonas no inundables por la morfología de su territorio, estableciéndose una escala de peligrosidad ante el riesgo desde el factor 1 (máxima peligrosidad) al factor 6 que representa la peligrosidad más baja. La relación de municipios con elevado riesgo de inundación ${ }^{62}$, así como las condiciones en ellos establecidas, se recoge en las Disposiciones Adicionales Primera y Segunda. La ciudad de Valencia no está incluida en esa relación. Además, los usos contemplados en el art. $22^{63}$ tienen prohibida su implantación en SNU si éste tiene riesgo de 2 a 4, y con limitaciones con riesgo 5 y 6. La programación y posterior desarrollo del suelo urbanizable afectado por este riesgo no puede comportar un incremento significativo del riesgo en su término municipal o en el de otros municipios potencialmente afectados, a excepción de los supuestos previstos en el art. 23.464. Esto es, los planes generales deben limitar

62 Plan de Acción Territorial de Riesgo de Inundación de la Comunidad Valenciana (PATRICOVA): Los municipios con mayor riesgo de inundación en la Comunidad Valenciana son: Albalat de la Ribera, Alboraya, Algemesí, Almassera, Almoradí, Alzira, Benimuslem, Bonrepós i Mirambell, Callosa del Segura, Catral, Cullera, Daya Nueva, Daya Vieja, Dolores, Formentera del Segura, Fortaleny, Orihuela, Polinyà del Xúquer, Quartell, Rafal, Ríola, Sollana, Tavernes Blanques y Tavernes de la Valldigna.

63 Art. 22 PATRICOVA. Limitaciones en suelo no urbanizable afectado por el riesgo de inundación "1. El suelo no urbanizable afectado por riesgo de inundación no podrá ser objeto de reclasificación como suelo urbano o urbanizable, excepto en los municipios con elevado riesgo de inundación, que se sujetarán a lo dispuesto en el artículo 19 de esta Normativa.

2. En suelo no urbanizable afectado por riesgo de inundación de nivel 2, 3 o 4, se prohíben los siguientes usos y actividades: viviendas; establos, granjas y criaderos de animales; estaciones de suministro de carburantes; industrias calificadas o con riesgo químico; establecimientos hoteleros y campamentos de turismo; centros hípicos y parques zoológicos; servicios funerarios y cementerios; depósitos de almacenamiento de residuos y vertederos; equipamientos estratégicos como centros de emergencia, parques de bomberos, cuarteles, centros escolares y sanitarios y pabellones deportivos cubiertos; infraestructuras puntuales estratégicas como plantas potabilizadoras y centros de producción, transformación y almacenamiento de energía. 3. En suelo no urbanizable afectado por riesgo de inundación de nivel 5 o 6, se prohíben los mismos usos y actividades señalados en el apartado anterior, excepto las viviendas y los establecimientos hoteleros, que sí son autorizables, previa adopción de las medidas de adecuación de la edificación que se impongan".

64 Art. 23.4. PATRICOVA. En particular, las industrias que almacenen, transformen, manipulen, generen, viertan, etc., productos que pudieran resultar ambientalmente perjudiciales para el 
los usos en el entorno de los marjales para que éstas puedan actuar como zonas de desbordamiento natural, evitando los impactos futuros que pudieran incidir negativamente en contra de su mantenimiento como zonas de interés ambiental.

A escala regional de la Comunidad Valenciana este plan sectorial define entre sus objetivos prioritarios los de gestionar las zonas inundables dentro del sistema territorial básico de la Infraestructura Verde prevista en el art.4 de la Ley 5/2014, de 25 de julio, de Ordenación del Territorio, Urbanismo y Paisaje, de la Comunidad Valenciana (LOTUP), Por ello, forman parte de la esta infraestructura las zonas críticas por la posible incidencia de riesgos naturales, directos e inducidos, de carácter significativo, que estén delimitados y caracterizados por la normativa de desarrollo, por la Estrategia Territorial de la Comunidad Valenciana o por los instrumentos que la desarrollen (art. 5.2.k. LOTUP) ${ }^{65}$. En el caso de la ciudad de Valencia, el PATRICOVA en coincidencia con la cartografía estatal establece para el viejo cauce un nivel de peligrosidad 3, frecuencia alta ( 25 años) y calado bajo $(<0.8 \mathrm{~m})$, y para el nuevo cauce un nivel 1, previéndose como medidas estructurales con alta prioridad el acondicionamiento del Bajo Turia y del Plan Sur en la desembocadura del río Turia (VC18), que comprende las actuaciones que persiguen la disminución del riesgo residual en el entorno de la ciudad de Valencia, de acuerdo con los condicionantes planteados por el Plan Sur. Incluye la adecuación de los azarbes en ambos márgenes del encauzamiento del Plan Sur, adaptación de la cabecera del mismo, e interceptación del barranco de Benimamet a través del de Andolça.

De modo semejante al contenido del Plan de gestión del riesgo anteriormente examinado, el PATRICOVA incide en la necesidad de urgente construcción de la presa de Villamarchante, proyecto que ya hemos enjuiciado anteriormente.

Otro instrumento para la gobernanza territorial del riesgo hídrico y afrontar las necesidades de organización y planificación es el Plan Especial ante el riesgo de inundaciones en la Comunidad Valenciana elaborado en 1999 por el Gobierno de la Comunidad Valenciana, revisado en 2010 mediante Decreto 81/2010, de 7 de mayo $^{66}$. El Plan fue elaborado siguiendo las pautas marcadas en la Norma Básica de Protección Civil, aprobada por el Real Decreto 407/1992, de 24 de abril, la Directriz Básica de Planificación de Protección Civil ante el Riesgo de Inundaciones, aprobada mediante Acuerdo del Consejo de Ministros de 9 de diciembre de 1994 y publicada mediante Resolución de 31 de enero de 1995, que establece el contenido al que deben ajustarse los Planes Especiales que elaboren las Comunidades Autónomas, así como la Ley 9/2002, de 12 de diciembre, de la Generalitat, de Protección Civil y Gestión de Emergencias de la Generalitat. El referido Plan ha sido revisado en el año 2015.

entorno de la actividad como consecuencia del arrastre, dilución o filtración, generados por el efecto de una Inundación y, en especial, para la salud humana, el suelo y/o el agua, la vegetación y la fauna, deberán ser evaluadas individualmente con el fin de justificar la autorización para su instalación en suelos sometidos a riesgo de inundación.

65 Almenar, 2015.

66 DOCV, de 12 de mayo de 2010. 
Finalmente, en la escala local figura el Plan General de Ordenación Urbana de Valencia como principal herramienta del gobierno local para ordenar usos en el territorio y, en relación con ello, para incorporar medidas que puedan contribuir a mitigar los riesgos inherentes a una población ${ }^{67}$. El Plan General de Valencia en fase de revisión (2010) se limita a recoger las determinaciones del PATRICOVA para este ámbito, y respecto a los nuevos sectores al norte de la ciudad "Alboraia", "Tavernes", "Vera 1" y "Vera 2", su problemática de inundabilidad asociada a los desbordamientos de los barrancos de Carraixet, han sido corregidos con el encauzamiento realizado y, en menor medida, a los problemas de drenaje de la cuenca menor del barranco de Palmaret. Se destaca la incidencia de este riesgo territorial en el propio diseño urbanístico por cuanto, al elaborar la ordenación pormenorizada de las áreas colindantes con cauces públicos, las zonas verdes y espacios libres deben disponerse a modo de barrera natural de protección.

Además, como medida iniciática y básica para la mitigación de este riesgo cada demarcación hidrográfica debe elaborar mapas de riesgo de inundación para las zonas identificadas en la evaluación preliminar del riesgo ${ }^{68}$. La información recogida en los mapas debe integrarse en el Sistema Nacional de Cartografía de Zonas Inundables ${ }^{69}$ (SNCZI) que constituyen la información fundamental en que se basarán los planes de gestión del riesgo de inundación ${ }^{70}$. A pesar de las limitaciones de la planificación territorial y urbanística para la implantación de usos en zonas inundables, la búsqueda de seguridad frente a la posibilidad de inundaciones catastróficas se ha abordado tradicionalmente instalando infraestructuras de carácter defensivo, orientadas, con más o menos fortuna, a modificar los rasgos del fenómeno disminu-

67 Olcina, 2004, p. 74.

68 González, 2009, p. 36.

69 MAGRAMA. Sistema Nacional de Cartografía de Zonas Inundables

70 El SNCZI determinó en su primer documento (2011) la designación de las Áreas de Riesgo Potencial Significativo de Inundación (ARPSI), las cuales indicaban las zonas donde se han identificado riesgos por inundación, ordenados en función de su grado de afectación, y en consecuencia se seleccionaban algunas de ellas (las más significativas) para desarrollar sus cartografías e incluirlas en el Plan de Gestión de Riesgos de Inundación. Actualmente, se han revisado las ARPSI y se han ampliado ligeramente.

En la zona de estudio, en el rio Turia en el tramo del nuevo cauce a la altura del cruce del AVE, se señalan los caudales para Q500 (periodo de retorno de 500 años) y el caudal máximo en régimen natural, también para 500 años. El primero de los datos es obtenido por la Confederación Hidrográfica del Júcar tras la elaboración de las cartografías de peligrosidad y riesgo de inundación en el año 2013, a partir de la hidrología e hidráulica correspondientes, determinados para periodos de retorno de 10, 50, 100 y 500 años.

El segundo dato se puede consultar también en el SNCZI, valor de dicho caudal determinado por el CEDEX para el CAUMAX. Ambos valores deberían ser aproximados, sin embargo, existe una diferencia sustancial de $2500 \mathrm{~m} 3 / \mathrm{s}$. El motivo fundamental es que el CAUMAX, elaborado para toda España, no se ajusta bien a la hidrología que existe en el Mediterráneo, presentando buenos ajustes en la determinación de caudales para periodos de retorno bajos, 10 y 25 años, pero distorsionándose mucho para periodos altos como 100 y 500 años.

Tras realizar consulta con el responsable del CAUMAX y personal del CEDEX, reconocen el sobredimensionamiento del CAUMAX para periodos de retorno altos en el Mediterráneo, por lo que debería ser tenidos en cuenta como referencia, los caudales obtenidos para el SNCZI, el decir, el determinado por la CHJ. 
yendo su peligrosidad o a dotar a los asentamientos humanos de solidez capaz de resistir la agresión ${ }^{71}$. En definitiva, de manera inaplazable las políticas públicas de prevención de riesgos deben revisarse, adaptándolas a la evolución política, jurídica y técnica. Los cambios deben orientarse hacia los nuevos desafíos importantes para el conjunto de la UE, en ámbitos tales como la eficiencia en el uso de los recursos naturales, el cambio climático, la biodiversidad y la prevención de catástrofes, entre ellas, las inundaciones.

\section{Conclusiones}

Transcurridos sesenta años de la catastrófica inundación que asoló la ciudad de Valencia procede realizar una reflexión sobre aquel suceso, abordándolo desde las diversas perspectivas que impone el actual contexto socio político, muy distinto al de aquella época. Se impone, en primer término, el análisis crítico de los supuestos fácticos que están en la base de la solución técnica que se adoptó con el fin de evitar que la ciudad de Valencia sufriera en el futuro nuevas inundaciones. Esos supuestos, en cuanto dato de partida, ofrecen serios reparos en cuanto a su exactitud y, consecuentemente, las actuaciones llevadas a cabo a partir de aquí se han visto afectadas por este vicio de origen y, por ello, no se ofrece una garantía suficientemente fundada de que la inundación no vuelva a repetirse. La medición del caudal efectuado por la Confederación Hidrográfica del Júcar, mediante el método Mings, con las deficiencias señaladas, es rectificada por los técnicos del Servicio Nacional de Meteorología que consideran que el caudal de la riada de 1957, a su paso por la ciudad de Valencia, no fue de 3.700 metros cúbicos por segundo, sino que en algunos momentos llegó a 6.000. Si esto es así, el caudal del nuevo cauce, calculado para avenidas máximas de 5.000 metros cúbicos por segundo, puede ser insuficiente para impedir una nueva riada. Nuevos factores aumentan el riesgo en relación con el año 1957, como son el cambio climático y el cambio antrópico que ha sufrido la cuenca baja del río Turia.

Los planes elaborados por la administración estatal que evalúan el riesgo sobre la ciudad de Valencia son el derivado del Reglamento del Dominio Público Hidráulico y el Plan de Gestión del Riesgo de Inundación de la Cuenca Hidrográfica del Júcar, elaborado por la Confederación Hidrográfica del Júcar. Los instrumentos emanados del siguiente nivel administrativo que evalúan el riesgo de la ciudad de Valencia, son el Plan de Acción Territorial de Riesgo de Inundación de la Comunidad Valenciana (PATRICOVA) y el Plan Especial ante el Riesgo de Inundación de la Comunidad Valenciana. Finalmente, en el nivel local figura el tratamiento que realiza el Plan General de Ordenación Urbana de la ciudad de Valencia. En ninguno de estos planes figura un riesgo significativo de inundación que pueda afectar a la ciudad de Valencia, aunque sí al área colindante ya que la infraestructura del nuevo cauce se construyó en razón se proteger a la ciudad.

71 Pérez, 2009, p. 98. 
Sin embargo, frente a esta ausencia de riesgo que se deduce de los referidos planes, se sitúan otras iniciativas administrativas que contradicen esa presumible seguridad, como son, fundamentalmente, los diversos proyectos elaborados y no ejecutados, consistentes en el recrecimiento de los cajeros del nuevo cauce en una altura de 1,5 metros que permitiría desaguar avenidas superiores a los 5.000 metros por segundo y propiciaría a la ciudad de Valencia una seguridad muy superior a la actual frente a esas grandes avenidas de las que, a lo largo de la historia han asolado a la ciudad.

La erradicación del riesgo descrito debe contemplarse, en primer lugar, dentro del marco normativo de la Unión Europea, de la que España forma parte, que ha elaborado un completo cuerpo doctrinal y jurídico, configurando sólidos principios como el de prevención y el de cautela que deben informar, no sólo las leyes de los estados miembros en relación con las amenazas de inundación, si no mover a actuaciones concretas, máxime si se trata de actuaciones tan simples como es el recrecimiento de las paredes de un cauce ya construido. El derecho de la Unión Europea representa una línea de fuerza que potencia la planificación hidrológica, y de manera correlativa el derecho interno de cada Estado miembro, para tratar de evitar, con anterioridad a su producción, los daños ecológicos, más que combatir posteriormente sus efectos.

Con independencia de lo anterior, en el caso de la Comunidad Valenciana parece oportuno aconsejar que debiera reforzarse el marco normativo. La actual dispersión de competencias repartidas entre distintas administraciones no facilita una adecuada toma de decisiones. En definitiva, el reto para el futuro radica en aumentar la base de conocimientos sobre vulnerabilidades y riesgos climáticos, el fortalecimiento de las leyes urbanísticas y la regulación de vacíos. Esta tarea es de mayor importancia que la de diseñar nuevos marcos, considerando que la UE ya cuenta con un cuerpo legislativo muy completo en materia de riesgo de inundación, en base a la cual debe reforzarse el derecho interno de cada país.

\section{Bibliografía}

ADGER, W. N. \& KELLY, P. M. Social vulnerability to climate change and the architecture of entitlements. Mitigation and Adaptation Strategies for Global Change, 4(3-4), 253-266. Doi: 10.1023/A:1009601904210, 1999.

Agencia Europea de Medio Ambiente (AEMA). Climate change, impacts and vulnerability in Europe 2012 - An indicator-based report, n ${ }^{0}$ 12/2012.

AGUDO GONZÁLEZ, J. Urbanismo y gestión del agua. Madrid: Iustel, 2007, 288 p.

AHERN, M, R.S. KOVATS, P. WILKINSON, R. FEW, \& F. MATTHIES. Global health impacts of floods: Epidemiologic evidence. Epidemiologic Reviews, 2005, vol. 27, p. 36-46.

ALMELA Y VIVES, F. Observaciones al margen del Turia, Las inundaciones en Valencia en 1957. Valencia: Cámara de la Propiedad Urbana de Valencia, XXI y XXII Extraordinario, 1959, 27 p. 
ALMENAR-MUÑOZ, M. Riesgos ambientales y territoriales. El riesgo de inundación. Los límites de la planificación. En La evaluación ambiental estratégica del planeamiento territorial y urbanístico. Factores ambientales, riesgos y afecciones legales (en especial en la Comunidad Valenciana). Tesis doctoral. Universitat Politècnica de València. doi:10.4995/Thesis/10251/59429. Valencia, p. 398: En http://hdl.handle.net/10251/59429, 2015.

Archivo Municipal de Valencia (AMV). Varios de Murs y Valladares y obra nueva del Río, oo, lio 8 doc. 1, Valencia, 28 de mayo de 1725.

ARMENGOT, R. Las lluvias intensas en la Comunidad Valenciana. Ministerio de Medio Ambiente. Madrid: Centro de Publicaciones, Ministerio de Medio Ambiente, 2002.

BETANCOR RODRÍGUEZ, A. Derecho Ambiental. La Ley, Madrid, 2014.

BIRKMANN, J., J. BIRKMANN, O. D. CARDONA, M. L. CARREÑO, A. H. BARBAT, M. PELLING, S. SCHNEIDERBAUER, S. KIENBERGER, M. KEILER, D. ALEXANDER, P. ZEIL \& T. WELLE. Framing vulnerability, risk and societal responses: the move framework. Natural Hazards, 2013, vol. 67(2), p. 193-211. doi: 10.1007/s11069013-055.

BOIRA MAIQUES, J.V. La ciudad de Valencia y su imagen pública. Valencia: Universidad de Valencia, Tesis doctoral. Departamento de Geografía, 1992.

BOIX, V. Historia de la Ciudad y Reino de Valencia. Valencia: Imp. de Benito Monfort. Tomo 1, 1845, $511 \mathrm{p}$.

CAMARASA BELMONTE, A. M. La estructura interna de las tormentas mediterráneas. Cuadernos de geografía, 1993, vol. 54. p. 169-188.

CARDONA OD, VAN AALST MK, BIRKMANN J, FORDHAM M, MCGREGOR G, \& MECHLER R. Determinants of risk: Exposure and vulnerability. En C. Field, V. Barros, T. F. Stocker \& D. Qin (Eds.), Managing the risks of extreme events and disasters to advance climate change adaptation. A Special Report of Working Groups I and II of the Intergovernmental Panel on Climate Change (IPCC). Cambridge, UK, and New York: Cambridge University Press, 2012, p. 65-108.

CARMONA P., RUIZ J. Las inundaciones de los ríos Júcar y Turia. Serie Geográfica, 2000, vol. 9, p. 49-69.

CRUZ ROMÁN, M. El 14 de octubre de 1957. En Las inundaciones en Valencia en 1957. Valencia: Cámara de la Propiedad Urbana de Valencia, XXI y XXII Extraordinario, 1959, p. 35.

DOMÉNECH GREGORI, V. La ordenación territorial y el riesgo de inundación: PATRICOVA. En Jornada Riesgo de inundación y planeamiento: La coordinación entre las administraciones públicas. 26 de septiembre de 2017. Valencia: Ilustre Colegio de Abogados de Valencia, 2017.

DOUE (Diario Oficial de la Unión Europea). Directiva 2007/60/CE del Parlamento Europeo y del Consejo, de 23 de octubre de 2007, relativa a la evaluación y gestión de los riesgos de inundación. Diario Oficial L 288 de 6/1 1/2007. p. 27-34. 
EMBID IRUJO, A. Aproximación a una teoría general de las sequías e inundaciones como fenómenos hidrológicos extremos. Revista Aranzadi de derecho ambiental, 2017, vol. 37, mayo-agosto 2017, p. 51-98.

ESCARTÍN ESCUDÉ, V.M. Incidencia en el modelo de ocupación del territorio de la gestión de los riesgos de inundación. Monografías de la Revista Aragonesa de Administración Pública, 2016, vol. 16, p. 233279.En<http://www.aragon.es/estaticos/GobiernoAragon/Organismos/ InstitutoAragonesAdministracionPublica/Documentos/XVI_120.pdf>.

ESTEVE PARDO, J. Derecho del medio ambiente. Madrid: Marcial Pons, 2005, 272 p.

FITA, F. Antigüedades romanas de Valencia (1835-1917). Edición digital a partir del Boletín de la Real Academia de la Historia, tomo 4, 1884, p. 1 16-144. <URI: htpp// www.cervantesvirtual. com/nd/ark: /59851/bmcüz7hl>.

FUCH, S. KUHLICKE, C. \& MEYER, V. Editorial for the special issue: vulnerability to natural hazards - the challenge of integration. Natural Hazards, 2011, vol. 58(2), p. 609-619. D (Doi; 10, 1007/s 11069-ol1-9825-5).

FULLANA SERRA, V. El plan Sur de Valencia. Conferencia impartida en el Ateneo Mercantil de Valencia, 6 de mayo de 2014.

GARCÍA, Ma . J. Técnicas preventivas de protección ambiental en el Régimen de Uso y Utilización del Dominio Público Hidráulico. Thomson-Aranzadi, 2003, 225 p.

GARCÍA, V. \& CARRASCO, A. Lluvias de intensidad y extensión extraordinarias causantes de las inundaciones de los días 13 y 14 de octubre de 1957 en las provincias de Valencia, Castellón y Alicante. Madrid: Servicio Meteorológico Nacional, Sección de Climatología, 1958, 67 p.

GENERALITAT VALENCIANA. Plan de Acción Territorial del Riesgo de Inundaciones en la Comunidad Valenciana (PATRICOVA), Revisión, Conselleria de Infraestructuras, Territorio y Medio Ambiente, 2015, disponible en: <www. citma.gva.es/ca/web/planificacion-territorial-e-infraestructura-verde/revisiondel-patricova-85207>.

GIL-GUIRADO, S. Deconstruyendo riesgos. Cuatro siglos de cambios en la vulnerabilidad y adaptación a las inundaciones y sequías en Murcia. Revista de historia moderna: Anales de la Universidad de Alicante, (Ejemplar dedicado a: Clima, riesgo y desastre a ambos lados del Atlántico durante la Edad Moderna. Respuestas políticas, técnicas y religiosas), 2017, vol. 35 p. 308-344.

GIL OLCINA, A.: Causas climáticas de las riadas. Avenidas fluviales e inundaciones en la cuenca del Mediterráneo. Alicante: Caja de Ahorros del Mediterráneo (CAM) e Instituto Universitario de Geografía. Universidad de Alicante, 1989, p. 15-30.

GIL OLCINA, A. Avenidas e inundaciones fluviales. Atlas temático de la Comunidad Valenciana. Alicante: Ed. Prensa Ibérica, 1991, p. 141-160.

GONZÁLEZ DEL TÁNAGO, M. Inundaciones y cambio climático. El cambio climático en España y sus consecuencias en el sector del agua. Madrid: Ed. Universidad Rey Juan Carlos, Aqualia, 2008, p. 53-66. 
GONZÁLEZ GARCÍA, J.L. (coord.). Mapas de riesgos naturales en la ordenación territorial y urbanística. Madrid: Ilustre Colegio Oficial de Geólogos, 2009, 101 p.

HARDOY, J. \& LANKAO ROMERO, P. Latin American cities and climate change. Challenges and options to mitigation and adaptation responses. Current Opinion in Environmental Sustainability, 2011 , vol. 3 (3), p. 158-163. doi: 10.1016/j. cosust.2011.01.004.

IBN KHAFAJA. Antología Poética (edición trilingüe árabe, valenciano, castellano). Ayuntamiento de Valencia, 2018.

INSAUSTI DE, P. \& VETGES TU MEDITERRÀNIA SLP. El Turia y la ciudad de Valencia. Propuestas de utilización del viejo cauce como parque urbano (1979-1990). Valencia: Colegio Territorial de Arquitectos de Valencia (CTAV), 1990, 254 p.

KUHLICKE, C., SCOLOBIG, A., TAPSELL, S., STEINFÜHRER, A. \& DE MARCHI, B. Contextualizing social vulnerability: Findings from case studies across Europe. Natural Hazards, 201 1, vol. 58(2), p. 789-810. doi: 10.1007/s 1 1069-01 1-9751-6

LAVELL, A. Degradación ambiental, riesgo y desastre urbano. Problemas y conceptos: Hacia la definición de una agenda de investigación. En M. A. Fernández (Comp.), Ciudades en riesgo. Degradación ambiental, riesgos urbanos y desastres. Lima: Red de estudios Sociales de Prevención de Desastres de América Latina (La Red), 1996, p. 21-60.

Legislación Unión Europea, Euro-Lex, Servicio de publicaciones UE, disponible en: <http://eur-lex.europa.eu/legal-content/ES/TXT/ ?uri=CELEX:12012E/TXT>. (consultada 20 de diciembre de 2017).

LLINARES G., QUIRÓS M., FULLANA V., DOMENECH R., PERIS O., GARCÍA A., ADALID M., \& PELLICER J. Actualización del Plan Sur de Valencia. Estudio informativo de los riesgos de que Valencia experimente una nueva inundación catastrófica. Ateneo Mercantil de Valencia, 2014. En <http://www.ateneovalencia.es/wpcontent/uploads/2014/11/IMPULSO-A-VALENCIA_ACTUALIZACIÓN-DELPLAN-SUR-DE-VALENCIA_.pdf $\geq$

LUTERBACHER, J., P. WERNER, J. E. SMERDON, L. FERNÁNDEZ-DONADO, F.J. GONZÁLEZ-ROUCO, D. BARRIOPEDRO, F.C. LJUNGQVIST, U. BÜNTGEN, E. ZORITA, S. WAGNER. European summer temperatures since Roman times. Environ. Res. Lett. 11 024001. 2016. <http://iopscience.iop.org/ article/10.1088/1748-9326/11/2/024001/pdf>

LLOP, J. De la institutió, govern politich, observâncies, costums, rentes y obligacions dels oficials de les illustres fabriques Vella, dita de Murs e Valls, y Nova dita del Riu, de la insigne, lleai y coronada Ciutat de Valencia. Valencia, f 2. Valencia, 1675, < http://viaf.org/viaf/186315750>.

MAGRIN, G., GARCÍA, C. G., CHOQUE, D. C., GIMÉNEZ, J. C., MORENO, A. R., NAGY, G. J., NOBRE, C. \& VILLAMIZAR, A. Latin America. En: PARRY, M. L., O. F. CANZIANI, J. P. PALUTIKOF, P. J. V. D. LINDEN \& C. E. HANSON (Eds.), Climate Change 2007: Impacts, Adaptation and Vulnerability. Contribution of Working Group II to the 
Fourth Assessment Report of the Intergovernmental Panel on Climate Change. Cambridge, UK, Cambridge University Press. 2007. p. 581-615

MARTÍ, F. Las gotas frías/danas/, ideas y conceptos básicos. Madrid: Instituto Nacional de Metereología, repositorio, AEMET, 2003, 24 p.

MARTÍN MATEO, R., Tratado de Derecho Ambiental. Madrid: Editorial Trívium, 1991, $520 \mathrm{p}$.

MELIÓ, V. La Junta de Murs i Valls. Historia de las Obras Públicas en la Valencia, del Antiguo Régimen, siglos XIV-XVIII. Valencia: Consell Valenciá de Cultura, 1991, $247 \mathrm{p}$.

MELLADO, L. La interrelación entre la ordenación del territorio y los nuevos planteamientos de gestión de los riesgos de inundación. VII Congreso Ibérico sobre Gestión y Planificación del Agua “Ríos Ibéricos +10. Mirando al futuro tras 10 años de DMA. 16/19 de febrero de 2011 , Talavera de la Reina, Toledo.

MENÉNDEZ REXACH, A. Zonas Inundables: delimitación y régimen jurídico. En Jornada riesgo de inundación y planeamiento: La coordinación entre las administraciones públicas. 26 de septiembre de 2017. Ilustre Colegio de Abogados de Valencia.

Ministerio de Agricultura, Alimentación y Medio Ambiente (MAGRAMA). Libro blanco del Agua. Documento de síntesis. Madrid, 2008, p. 34. En http://www. magrama.gob.es/es/agua/temas/planificacion-hidrologica/sintesis_tcm728955.pdf.

Ministerio de Agricultura, Alimentación y Medio Ambiente (MAGRAMA). Sistema Nacional de Cartografía de Zonas Inundables. Madrid, 2014. En <http://www. magrama.gob.es/es/agua/temas/gestion-de-los-riesgos-de-inundacion/snczi/>

Ministerio de Agricultura, Alimentación y Medio Ambiente (MAPAMA). Guía técnica de apoyo a la aplicación del reglamento del dominio público hidráulico en las limitaciones a los usos del suelo en las zonas inundables de origen fluvial. Madrid, 2017. En <http://www.mapama.gob.es/imagenes/es/guia-tecnicardph-usos-suelo-zonas-inundables_tcm7-466382.pdf>

Observatorio de la Sostenibilidad en España. Cambios de ocupación del suelo en España, Implicaciones para la sostenibilidad. Madrid: Ministerio de Fomento, 2006, 485 p.

OLCINA CANTOS, J. El factor climático y la ordenación del territorio: los riesgos climáticos. Situaciones de riesgo climático en España. Jaca, Instituto Pirenaico de Ecología: (Creus Novau, J., edit.). Asociación de Geógrafos Españoles, 1995, p.15-69.

OLCINA CANTOS, J. Temporales de octubre de 1957 en el Levante español. Nimbus $n^{0}$ 4. Revista de climatología, meteorología y paisaje,1999, p. 129-152.

OLCINA CANTOS, J. Riesgos de inundaciones y ordenación del territorio en la escala local. El papel del planeamiento urbano municipal. Boletín de la Asociación 
de Geógrafos Españoles, vol. 37, (Monográfico «Agua y Ciudad»), Madrid, Asociación de Geógrafos Españoles, 2004, p. 49-84.

OLCINA CANTOS, J. Prevención de riesgos: cambio climático, sequías e inundaciones en Panel científico-técnico de seguimiento de la política del agua. Alicante: Universidad de Alicante, 2008. 240 p. <https:/fnca.eu/images/documentos/ politica/informes/anexo.pdf>

PÉREZ APARISI, Hasta aquí llegó la riada. Valencia: Ayuntamiento de Valencia, 1997, $344 \mathrm{p}$.

PÉREZ MORALES, A. La valoración del riesgo de inundación en los instrumentos de gobernanza municipales del sur de Murcia. Investigaciones geográficas, vol. 48, 2009, p. 97-123.

PÉREZ-MORALES, A., GIL-GUIRADO S., \& OLCINA J. La información catastral como herramienta para el análisis de la exposición al peligro de inundaciones en el litoral mediterráneo español, Revista Latinoamericana de Estudios Urbano Regionales, vol. 42, n 127, Septiembre 2016, p. 231-256.

PÉREZ PUCHE, F. Hasta aquí llegó la riada, Valencia: ed. Ayuntamiento de Valencia, 1997.

Plan de Gestión del Riesgo de Inundación. Demarcación Hidrográfica del Júcar. Valencia, 2015.

Plan Especial frente al riesgo de inundaciones. Generalitat Valenciana. 2015.

Proyecto informativo de acondicionamiento del nuevo cauce del río Turia. Entidad estatal ACUAMED, Madrid, 2007.

RIVERA NEBOT, A. Las lluvias intensas en la Comunidad Valenciana: Generalidades y causas. Riada en Valencia octubre 1957. Tiempo severo.es, 2010. En <http:// www.tiemposevero.es/ver-reportaje.php?id=257 $\geq$.

ROGER FERNÁNDEZ, G. Para comprender el urbanismo español (de una vez por todas). Madrid: Iustel, 2011, 176 p.

ROMERO SAURA, F. El plan general como destinatario directo de políticas territoriales (Comunidad Valenciana). I Congreso de Urbanismo y Ordenación del Territorio del Colegio de Ingenieros Caminos, Canales y Puertos, Valencia, 2008.

SAURÍ, D., SERRA A., OLCINA, J. \& VERA, J.F. Climate change and Europe's regions: Key findings. Case study Spanish Mediterranean coast. En S. Greiving (Coord.), ESPON Climate Change and Territorial E_ects on Regions and Local Economies. 201 1, pp. 30-39. En <http://bit.ly/ltmzTG7 2 .

SELVA ROYO, J.R. Antecedentes y formación del Plan General de Valencia de 1966. Cuadernos de Investigación Urbanística CIUR, 2014, vol. 97 (noviembre/ diciembre 2014) p. 1-68.

SERRANO, A. Catástrofes y cambio climático. Revista sistema digital. 16 marzo 2017. Madrid. En <https://www.fundacionsistema.com/catastrofes-y-cambioclimatico/>.

SORRIBES \& MONRABAL, J. Valencia 1940-2014. Construcción y destrucción de la ciudad. Valencia: Publicacions Universitat de València, 2015, 468 p. 
THORNDYCRAFT, V. R., BENITO, G., LLASAT, M. C. \& BARRIENDOS, M. Palaeofloods, historical data \& climatic variability: applications in flood risk assessment. In: Palaeofloods, Historical Data and Climatic Variability: Applications in Flood Risk Assessment. Madrid: (ed. by V. R. Thorndycraft, G. Benito, M. Barriendos \& M. C. Llasat), 3-9, 2003, Centro de Ciencias Medioambientales, p. 1-118.

WELZ, J \& KRELLENBERG, K., Vulnerabilidad frente al cambio climático en la Región Metropolitana de Santiago de Chile: posiciones teóricas versus evidencias empíricas. Revista Latinoamericana de Estudios Urbano Regionales, vol. 42, $\mathrm{n}^{\circ}$ 125, enero 2016, p. 251-272.

(c) Copyright: Scripta Nova, 2019.

Ficha bibliográfica:

ROMERO ALOY, María Jesús; ALMENAR-MUÑOZ, MERCEDES; FULLANA SERRA, Vicente. En torno a la riada de 1957 en la ciudad de Valencia Scripta Nova. Revista Electrónica de Geografía y Ciencias Sociales. Barcelona: Universidad de Barcelona, 15 de septiembre de 2019, vol. XXII, nº 622. [ISSN: 1138-9788] 